April 1999 - NREL/SR-500-26173

\title{
Design of a Tapered and Twisted Blade for the NREL Combined Experiment Rotor
}

\section{March 1998 - March 1999}

P. Giguère and M.S. Selig

Department of Aeronautical and Astronautical Engineering University of Illinois at Urbana-Champaign Urbana, Illinois

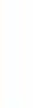


April 1999 • NREL/SR-500-26173

\section{Design of a Tapered and Twisted Blade for the NREL Combined Experiment Rotor}

\section{March 1998 - March 1999}

P. Giguère and M.S. Selig

Department of Aeronautical

and Astronautical Engineering

University of Illinois at Urbana-Champaign

Urbana, Illinois

NREL Technical Monitors: James L. Tangler and David A. Simms

Prepared under Subcontract No. XAF-4-14076-03

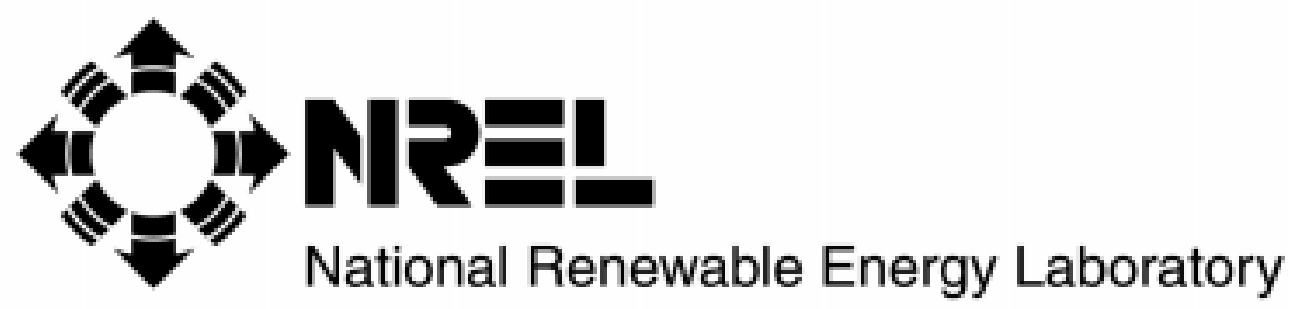

1617 Cole Boulevard

Golden, Colorado 80401-3393

NREL is a U.S. Department of Energy Laboratory

Operated by Midwest Research Institute - Battelle • Bechtel

Contract No. DE-AC36-98-GO10337 


\section{NOTICE}

This report was prepared as an account of work sponsored by an agency of the United States government. Neither the United States government nor any agency thereof, nor any of their employees, makes any warranty, express or implied, or assumes any legal liability or responsibility for the accuracy, completeness, or usefulness of any information, apparatus, product, or process disclosed, or represents that its use would not infringe privately owned rights. Reference herein to any specific commercial product, process, or service by trade name, trademark, manufacturer, or otherwise does not necessarily constitute or imply its endorsement, recommendation, or favoring by the United States government or any agency thereof. The views and opinions of authors expressed herein do not necessarily state or reflect those of the United States government or any agency thereof.

Available to DOE and DOE contractors from:

Office of Scientific and Technical Information (OSTI)

P.O. Box 62

Oak Ridge, TN 37831

Prices available by calling 423-576-8401

Available to the public from:

National Technical Information Service (NTIS)

U.S. Department of Commerce

5285 Port Royal Road

Springfield, VA 22161

703-605-6000 or 800-553-6847

or

DOE Information Bridge

http://www.doe.gov/bridge/home.html 


\section{Foreword}

Previous phases of experimenting with the Combined Experiment Rotor (CER) of the National Renewable Energy Laboratory (NREL) have provided test results from two constant-chord blade sets. The first blade set had no twist whereas the second had twist. As the next step, the design of a tapered/twisted blade for the CER was contracted out to the Department of Aeronautical and Astronautical Engineering of the University of Illinois at Urbana-Champaign. This blade design work consisted of a systematic trade-off study where many blade configurations were compared to determine how much the design constraints affected blade performance. Based on the results of the tradeoff study, a blade having a linear taper and nonlinear twist, and that uses the S809 airfoil, was selected as the new CER blade. An extended version of this blade was also designed for a two-bladed rotor configuration. The new CER blades are presently being built by an independent blade manufacturer. NREL plans to test the new blades under constant- and variable-speed operations.

James L. Tangler

National Renewable Energy Laboratory - National Wind Technology Center

1617 Cole Boulevard.

Golden, Colorado 80401 USA

E-mail: james_tangler@nrel.gov

Phone: 303-384-6934

Fax: 303-384-6901 


\section{Preface}

A tapered/twisted blade set was designed for the Combined Experiment Rotor (CER) of the National Renewable Energy Laboratory. The objective was to build on the knowledge base of the previous CER tests conducted with constant-chord/untwisted blades and constant-chord/twisted blades. Such CER tapered/twisted blades will yield performance that is more representative of commercial blades. In addition, these new blades will continue to satisfy the scientific needs for fundamental research in rotor aerodynamics.

This blade design work for the CER was performed during the summer of 1997 while the first author was at the National Wind Technology Center. The authors would like to thank NREL for providing funding under subcontract XAF-4-14076-03 and the opportunity to design new blades for the CER. Also, the authors would like to thank James L. Tangler, David A. Simms, and Lee J. Fingersh of NREL for their feedback and suggestions throughout this blade design work. The comments of Dr. Michael C. Robinson and C.P. (Sandy) Butterfield of NREL were also appreciated. 


\section{Summary}

A tapered/twisted blade was designed to operate on the Combined Experiment Rotor (CER) of the National Renewable Energy Laboratory (NREL), which is a stall-regulated downwind wind turbine having a rated power of 20 kilowatt. The geometry of the new blade set was optimized based on annual energy production subject to the constraints imposed on the design. These constraints were mainly related to scientific needs for fundamental research in rotor aerodynamics. A trade-off study was conducted to determine the effect of the different design constraints. Based on the results of this study, which considered nonlinear twist and taper distributions as well as the NREL S809, S814, S822 and S823 airfoils, a blade having a linear taper and a nonlinear twist distribution that uses the S809 airfoil from root to tip was selected. This blade configuration is the logical continuation of the previous constant-chord twisted and untwisted blade sets and will facilitate comparison with those earlier blades. Despite the design constraints based on scientific needs, the new blade is more representative of commercial blades than the previous blade sets.

The new blade was designed to be applicable for three- and two-bladed rotor configurations. To enhance the performance of the new blade in a two-bladed rotor configuration instead of the baseline three-bladed rotor, an increase in blade span was investigated, which led to the design of an extended blade having a $10 \%$ increase in span. Furthermore, an increase in rotor speed was also investigated. A two-bladed rotor making use of extended blades and rotating at a speed $8 \%$ faster than the baseline speed or revolution per minute setting was found to yield comparable power output to that of the new blades in a three-bladed rotor configuration. Results for the CER equipped with the new blades (baseline and extended blades) in terms of mechanical power output, rotor thrust as well as lift coefficient and axial inflow distributions along the blade span are presented. Even though the new blades were designed for constant-speed operations, they can also be used for fundamental research in variable-speed operations. To facilitate the selection of the most appropriate rotor configuration for the NREL variable-speed test bed using the new blades, results showing the power coefficient as a function of the tip-speed ratio for various pitch settings are presented. Finally, recommendations for future blade sets for the CER are also given. 


\section{Contents}

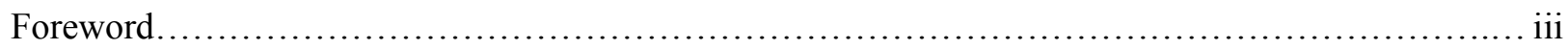

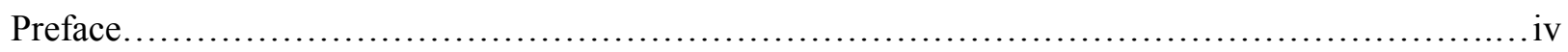

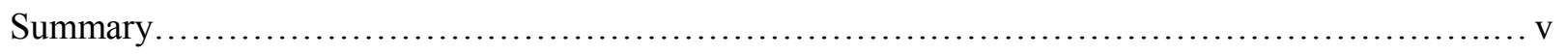

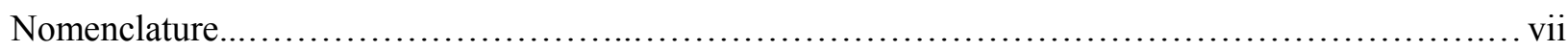

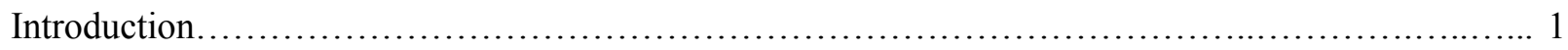

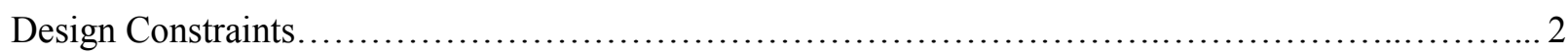

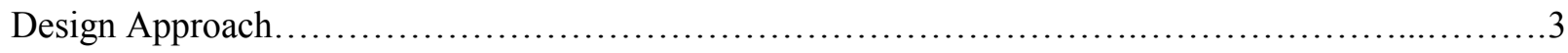

Design Trade-offs and Blade Geometry Optimization....................................... 4

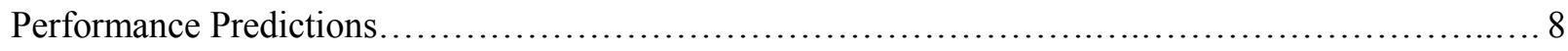

Conclusions and Recommendations................................................... 14

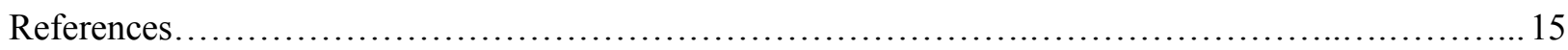

Appendix A: Tabulated Data for the Tapered/Twisted CER blade $\ldots \ldots \ldots \ldots \ldots \ldots \ldots \ldots \ldots \ldots \ldots \ldots \ldots \ldots$

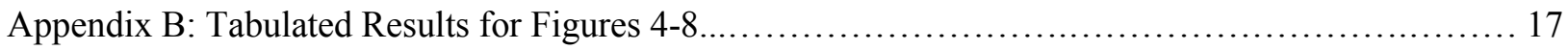




\section{List of Figures}

1. Planform of the baseline tapered/twisted CER blade (three-bladed rotor configuration)........... 6

2. Planform of the extended tapered/twisted CER blade (two-bladed rotor configuration)............ 6

3. Final twist distribution of the tapered/twisted CER blade $\ldots \ldots \ldots \ldots \ldots \ldots \ldots \ldots \ldots \ldots \ldots \ldots \ldots \ldots \ldots$

4. Power curves for the tapered/twisted CER blade.......................................... 8

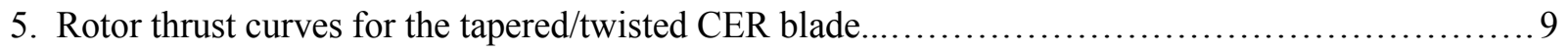

6. Lift coefficient distribution along the span for the tapered/twisted CER blade.................... 10

7. Axial inflow coefficient distribution along the span for the tapered/twisted CER blade..............11

8. Power coefficient vs. tip-speed ratio for the tapered/twisted CER blade.......................... 12

\section{List of Tables}

1. Results of the blade configuration trade-off study ....................................... 5

\section{Nomenclature}

c $\quad$ Blade chord

HD Hub diameter

$\mathrm{R} \quad$ Blade radius

r Radial distance along the blade span from the center of the rotor

N Newton 


\section{Introduction}

The Combined Experiment Rotor (CER) of the National Renewable Energy Laboratory (NREL) has a

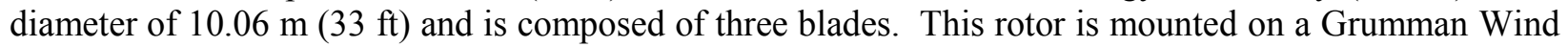
Stream 33 horizontal axis wind turbine (HAWT), which is a stall-regulated downwind machine having a rated power of 20 kilowatt $(\mathrm{kW})$ and operating at a speed of 72 revolutions per minute $(\mathrm{rpm}) .{ }^{1}$ To date, two blade sets were tested with this wind turbine for fundamental research in rotor aerodynamics. The first blade set was composed of constant-chord/untwisted blades and the second set had constantchord/twisted blades. Both of these blade sets were built with a chord of $457 \mathrm{~mm}$ (18 in.) and used the NREL S809 airfoil along the entire span. In addition, one blade of each set was instrumented with chordwise pressure taps and a 5-hole probe at five spanwise locations, namely at $30 \%, 47 \%, 63 \%, 80 \%$, and $95 \%$ span. These two blade sets were extensively tested and the results of those experiments can be found in Refs. 2 and 3.

The objective of this work was to design a third blade set for the CER having both taper and twist. In contrast with the two other blade sets, the blade geometry for the new set was to be designed for maximum annual energy production. Because of the need for fundamental research in rotor aerodynamics and practical aspects, constraints were imposed on the design. An important part of this work was to conduct a study of the design trade-offs to determine the effect of those constraints on the energy capture of the rotor. Another objective was to determine the necessary modifications to the blade geometry and operating rpm for a two-bladed rotor configuration. This report describes the approach and process used to design a tapered/twisted blade, and provides performance predictions for the CER equipped with the new blades. The performance of the CER equipped with the new blade set was also investigated under variable-speed operation. 


\section{Design Constraints}

NREL provided the design constraints for the tapered/twisted CER blades. ${ }^{4}$ Some practical constraints were imposed to facilitate the instrumentation of the new blades in a manner similar to the previous CER blade sets. Other constraints were imposed to ensure consistency with the previous blade sets for ease of comparison of the data. The design constraints for the tapered/twisted blades for the CER were as follows:

- A blade span of $5.03 \mathrm{~m}$ (16.5 ft) including a 102-mm (4-in.) tip shape for the baseline three-bladed rotor

- A rated power of $20 \mathrm{~kW}$

- A cone angle of 3.4 degrees

- Keep distance from pitch axis to the leading edge less than $584 \mathrm{~mm}$ (23 in.) so that the 5-hole probes do not hit the tower

- A minimum chord of $305 \mathrm{~mm}$ (12 in.) to allow for the installation of pressure taps and instrumentation on the instrumented blade

- A fixed chord length of $457 \mathrm{~mm}$ (18 in.) at $80 \%$ of the blade span for comparison of the pressure data with the previous blade sets

- Use the $\mathrm{S} 809^{5}$ airfoil for as much of the blade span as possible to facilitate comparison with the previous blade sets

- Transition to the $\mathrm{S} 814^{5}$ root airfoil from the S809 airfoil not to begin before $47 \%$ of the blade span. 


\section{Design Approach}

The computer programs PROPID ${ }^{6,7}$ and PROPGA ${ }^{7,8}$ were used to carry out the blade design process. PROPID is an inverse design and analysis method for HAWTs that is based on the bladeelement/momentum theory PROP code. ${ }^{9}$ The inverse design capabilities of PROPID allow for the desired performance and aerodynamic characteristics of the rotor to be prescribed from which the blade geometry and corresponding operating conditions are determined. In the present design work, the inverse design capability of PROPID was used to limit the mechanical power output of the CER to $20 \mathrm{~kW}$. Also, the Prandtl tip-loss model was used and the Corrigan post-stall model ${ }^{10}$ was incorporated into PROPID to modify the two-dimensional airfoil for three-dimensional effects. ${ }^{11}$ PROPGA is a genetic algorithm based optimization method for HAWTs that relies on PROPID for the analysis of the possible blade/rotor designs. Given a set of design constraints/requirements, bounds for the parameters to be optimized, and a figure of merit (objective function) for the optimization, PROPGA provides the optimum blade geometry.

As a first and important step in the design process, the trade-offs between various blade configurations and airfoils were investigated to determine the effect of the design constraints on the energy capture of the rotor. For each blade configuration considered, the blade geometry was optimized for maximum gross annual energy production (GAEP) using PROPGA. Once the final blade geometry was selected, PROPID was used to finalize the blade twist distribution and pitch setting. Particular attention was given to obtaining smooth stall characteristics along the entire blade span. Following the design of the blades for the baseline three-bladed rotor, PROPID was also used to determine the necessary modifications to the blade geometry and operating rotor speed for a two-bladed rotor configuration. In addition, PROPID was used to provide performance predictions with greater accuracy under constant-speed and variable-speed operations.

Throughout the design process, the GAEP (assuming a 100\% generator efficiency) was computed based on a Rayleigh wind-speed distribution having an average wind speed of $7.2 \mathrm{~m} / \mathrm{s}(16 \mathrm{mph})$, which is representative of the windy months at NREL. Also, the power output of the rotor was computed up to a wind speed of $17.9 \mathrm{~m} / \mathrm{s}(40 \mathrm{mph})$ using standard atmospheric conditions at the altitude of the National Wind Technology Center (1,829 $\mathrm{m}$ or $6,000 \mathrm{ft})$. The number of segments used along the blade span was 10 for a PROPGA run and 20 when using PROPID outside the optimization scheme of PROPGA. In predicting rotor performance, airfoil data obtained from wind tunnel experiments over a range of Reynolds numbers were used. To interpolate between Reynolds numbers, a logarithmic scheme was used for the drag and linear interpolation was used for the lift. Similar schemes were also used when necessary to extrapolate the data above the largest Reynolds number in the available data. 


\section{Design Trade-offs and Blade Geometry Optimization}

The trade-off study was subdivided into a number of tasks that were defined by NREL. ${ }^{4}$ The first two tasks were to optimize blades without any of the design constraints to provide a basis for comparison. The chord and twist distributions as well as the blade pitch were optimized for three sets of NREL airfoils: ${ }^{5}$

- $\mathrm{S} 809$ from root to tip

- S814 at the root (0\%-35\% span) and S809 at the tip (75\%-100\% span)

- $\mathrm{S} 823$ at the root (0\%-35\% span) and S822 at the tip (75\%-100\% span).

For the two cases with multiple airfoils along the blade span, a linear transition was used between the two airfoils. The case with the S822 and S823 airfoils was added to the NREL task list because of the objective to maximize energy capture. These two airfoils were designed for small blades, and thus have design Reynolds numbers that are closer to the operating range of the CER as compared with the S809 and S814 airfoils, which were designed for medium-size wind turbines. It is important to note, however, that the S822 and S823 airfoils were designed after the first blade set for the CER was designed and built. The selection of the S809 airfoil was initially based on the need to use a well-documented airfoil and at the time of the design of the first blade set for the CER, the S809 airfoil had been extensively tested at the Delft wind tunnel. ${ }^{12}$ For the second blade set, the $\mathrm{S} 809$ airfoil was used for consistency to provide a basis for comparison with the first blade set. The S814 airfoil was also tested in the Delft wind tunnel at a later time. ${ }^{13}$ The airfoil data gathered with the S809 and S814 were used in the blade optimization process. For the S822 and S823 airfoils, the data used were obtained from the University of Illinois at UrbanaChampaign low-turbulence subsonic wind tunnel. ${ }^{14,15}$ The data sets for each airfoil used in the design process were for clean-surface conditions. Note that the data below a Reynolds number of 1,000,000 for the S809 airfoil, and below 700,000 for the S814 airfoil, were obtained from logarithmic extrapolations for the drag and linear extrapolations for the lift.

The results of the trade-off study are summarized in Table 1. The blades optimized without any chord and twist constraints using the S809 airfoil with or without the S814 root airfoil provided equivalent energy capture, which was about 3\% less than the GAEP of the blade making use of the S822 and S823 airfoils. This 3\% increase in GAEP by using the S822 and S823 airfoils was not judged to be significant enough to offset the desire to preserve consistency with the S809 airfoil for the new CER blades. A thicker airfoil inboard having a higher maximum lift coefficient would, of course, provide a blade design more representative of commercial blades. Therefore, the S814 airfoil was further considered in the design.

Among the three blades optimized without any constraints, all had tip-chord lengths larger than $305 \mathrm{~mm}$ (12 in.). Therefore, the minimum chord constraint did not cause a loss in performance. It was found that constraining the blade to a linear taper was not significantly detrimental to the energy capture as long as the twist distribution was nonlinear. Consequently, a linear taper was adopted. The constraint that had the most significant negative impact on the energy capture was the 457-mm (18-in.) chord length constraint at $80 \%$ blade span, which resulted in a loss in energy capture that ranged from $2.5 \%$ to $7 \%$ depending on the tip chord. For a given set of constraints, the optimized blades that made use of the S814 airfoil inboard provided slightly better energy capture than blades using only the S809 airfoil.

Because of the importance of the 457-mm (18-in.) chord constraint at $80 \%$ of the blade span for comparison of pressure data with the existing blade sets, the planform of the new blades was designed around that constraint. Consequently, the design of the blade planform was oriented towards a more "scientific" blade rather than a "commercial" blade. Nevertheless, the new blades are more representative of commercial blades than the previous two blade sets. According to the selection of a planform based on scientific needs, it seemed logical to design the blades with only the S809 airfoil. Apart from the ease of 
comparison with the previous CER blades, there is no added confusion in the aerodynamics of modeling the $3 \mathrm{D}$ post-stall effects when only the S809 airfoil is used on the new blades. Also, there is no blending between airfoils, and thus the uncertainty level in the design process is reduced.

Table 1: Results of the blade configuration trade-off study given in terms of percentage difference in gross annual energy production (GAEP)

\begin{tabular}{|c|c|c|}
\hline \multicolumn{3}{|c|}{ Blade Configuration Tradeoff Study } \\
\hline \multicolumn{3}{|c|}{ 1) Cases with different airfoils and no constraint } \\
\hline \multicolumn{3}{|l|}{ Airfoils } \\
\hline Root (0\%-30\% r/R) & Tip (75\%-100\% r/R) & \% diff. in GAEP \\
\hline S823 & S822 & baseline \\
\hline S814 & S809 & $-3.0 \%$ \\
\hline S809 & S809 & $-2.7 \%$ \\
\hline \multicolumn{3}{|c|}{ 2) Cases with the S814/S809 airfoils } \\
\hline \multicolumn{2}{|l|}{ Constraints } & $\%$ diff. in GAEP \\
\hline \multicolumn{2}{|l|}{ No constraint } & baseline \\
\hline \multicolumn{2}{|c|}{ Minimum chord of $305 \mathrm{~mm}$ (12 in.) } & same as baseline \\
\hline \multicolumn{2}{|c|}{ Linear taper and nonlinear twist } & $-0.1 \%$ \\
\hline \multicolumn{2}{|c|}{ Same as above with chord of $457 \mathrm{~mm}(18 \mathrm{in}$.$) at 80 \% \mathrm{r} / \mathrm{R}$} & $-2.5 \%$ \\
\hline \multicolumn{2}{|c|}{ Same as above with tip chord of $305 \mathrm{~mm}$ (12 in.) } & $-2.7 \%$ \\
\hline \multicolumn{2}{|c|}{ Same as above with tip chord of $356 \mathrm{~mm}$ (13.5 in.) } & $-3.7 \%$ \\
\hline \multicolumn{2}{|c|}{ Same as above with tip chord of $381 \mathrm{~mm}$ (15 in.) } & $-5.1 \%$ \\
\hline \multicolumn{2}{|c|}{ Same as above with tip chord of $419 \mathrm{~mm}$ (16.5 in.) } & $-6.9 \%$ \\
\hline \multicolumn{3}{|c|}{ 3) Cases with the S809 airfoil } \\
\hline \multicolumn{2}{|l|}{ Constraints } & $\%$ diff. in GAEP \\
\hline \multicolumn{2}{|l|}{ No constraint } & baseline \\
\hline \multicolumn{2}{|c|}{ Minimum chord of $305 \mathrm{~mm}$ (12 in.) } & same as baseline \\
\hline \multicolumn{2}{|c|}{ Linear taper and nonlinear twist } & $-0.3 \%$ \\
\hline \multicolumn{2}{|c|}{ Same as above with chord of $457 \mathrm{~mm}$ (18 in.) at $80 \% \mathrm{r} / \mathrm{R}$} & $-3.5 \%$ \\
\hline
\end{tabular}

Given a 457-mm (18-in.) chord at $80 \%$ blade span and the use of a linear taper, the design of the blade planform was reduced to the selection of the tip chord. For optimum energy capture, a 305-mm (12-in.) tip chord would have been best but because of the desire to operate the new blade set in a two-bladed rotor configuration, a rotor with a slightly larger solidity was selected. More precisely, a 356-mm (14-in.) tip chord appeared to be the best compromise between operating the blades in a three-bladed and twobladed rotor configuration. At the root, the chord tapers from a maximum of $737 \mathrm{~mm} \mathrm{(29} \mathrm{in.)} \mathrm{at} 25 \%$ blade span to the hub diameter at 14\% span. The taper ratio of the baseline blade is 2.1 (29:14 in.). The planform of the proposed blade for the third set of the CER, which is later referred to as the baseline tapered/twisted CER blade, or simply the baseline blade, is shown in Figure 1.

Using PROPID, it was found that increasing the blade span by $10 \%$ was a good compromise between enhancing the performance of the baseline blade in a two-bladed rotor configuration and limiting the increase in blade loads. The linear taper was preserved in extending the baseline blade, which gave a tip chord of $305 \mathrm{~mm}$ (12 in.). Figure 2 depicts the baseline blade with the $10 \%$ span extension. (Note that the $\mathrm{x}$-axis extends to a $\mathrm{r} / \mathrm{R}$ of 1.1 , and $\mathrm{R}$ remains the span of the baseline blade). With the blade extension, the taper ratio of the blade is 2.4 . The blade with the $10 \%$ increase in span is referred to as the extended tapered/twisted CER blade. The tabulated data for the geometry of the baseline blade including the $10 \%$ span extension is given in Appendix A. Both blade spans can be accommodated by the same mold having $110 \%$ the span of the baseline blade. 


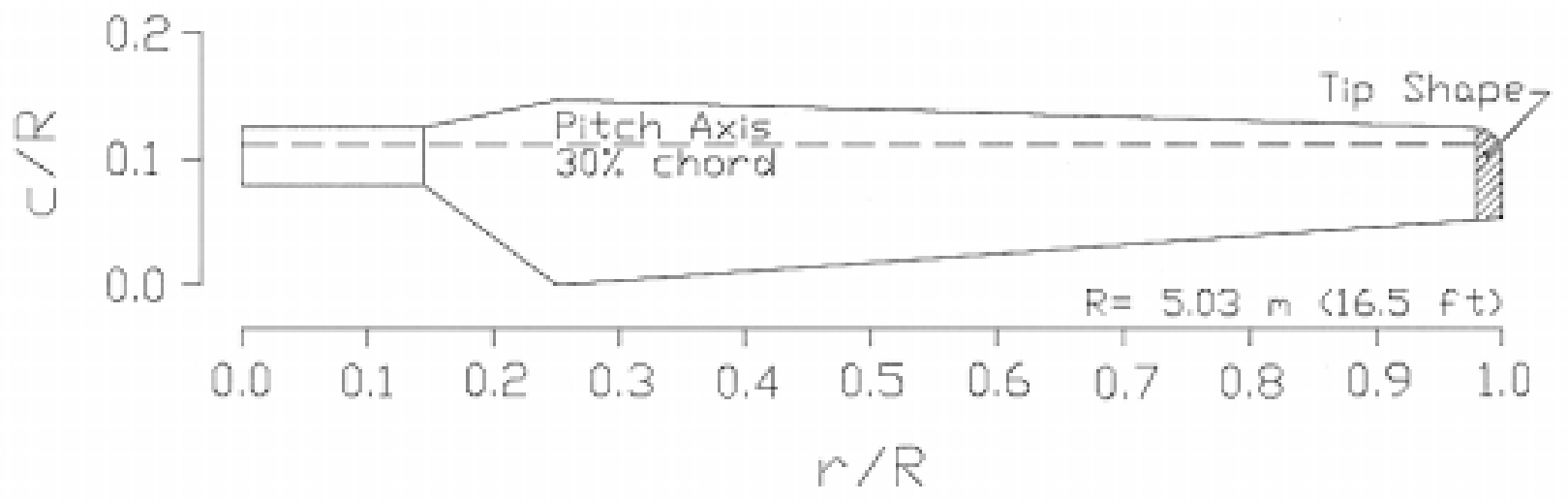

Fig. 1: Planform of the baseline tapered/twisted CER blade for the three-bladed rotor configuration (the normalized chord is $\mathrm{c} / \mathrm{R}$ and the normalized radial position is $\mathrm{r} / \mathrm{R}$ )

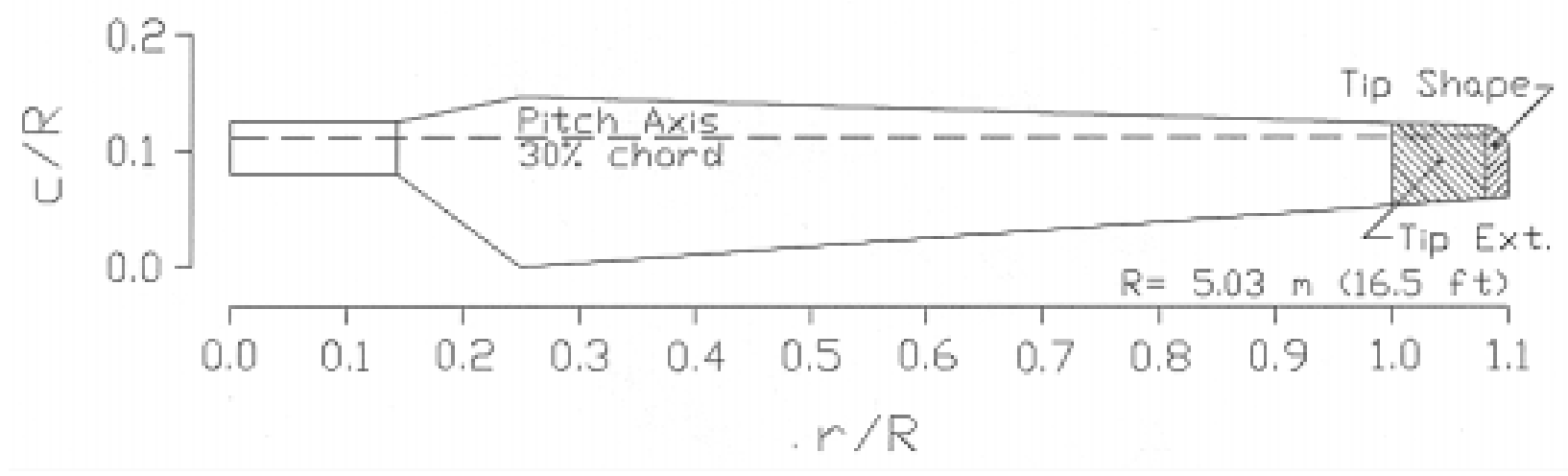

Fig. 2: Planform of the extended tapered/twisted CER blade for the two-bladed rotor configuration (the normalized chord is $\mathrm{c} / \mathrm{R}$ and the normalized radial position is $\mathrm{r} / \mathrm{R}$ )

The twist distribution and the pitch setting of the baseline blade were optimized for maximum GAEP. Particular attention was also given to obtaining a smooth power curve and smooth transition to stall from root to tip. The final twist distribution is shown in Figure 3 and the optimum pitch setting was 5 degrees (with pitch defined at $75 \%$ of the blade span). Finally, no new tip shape was designed for the new CER blades. Consequently, the same tip geometry used on the existing blade sets should be scaled down according to the tip-chord lengths of the baseline and extended blades. 


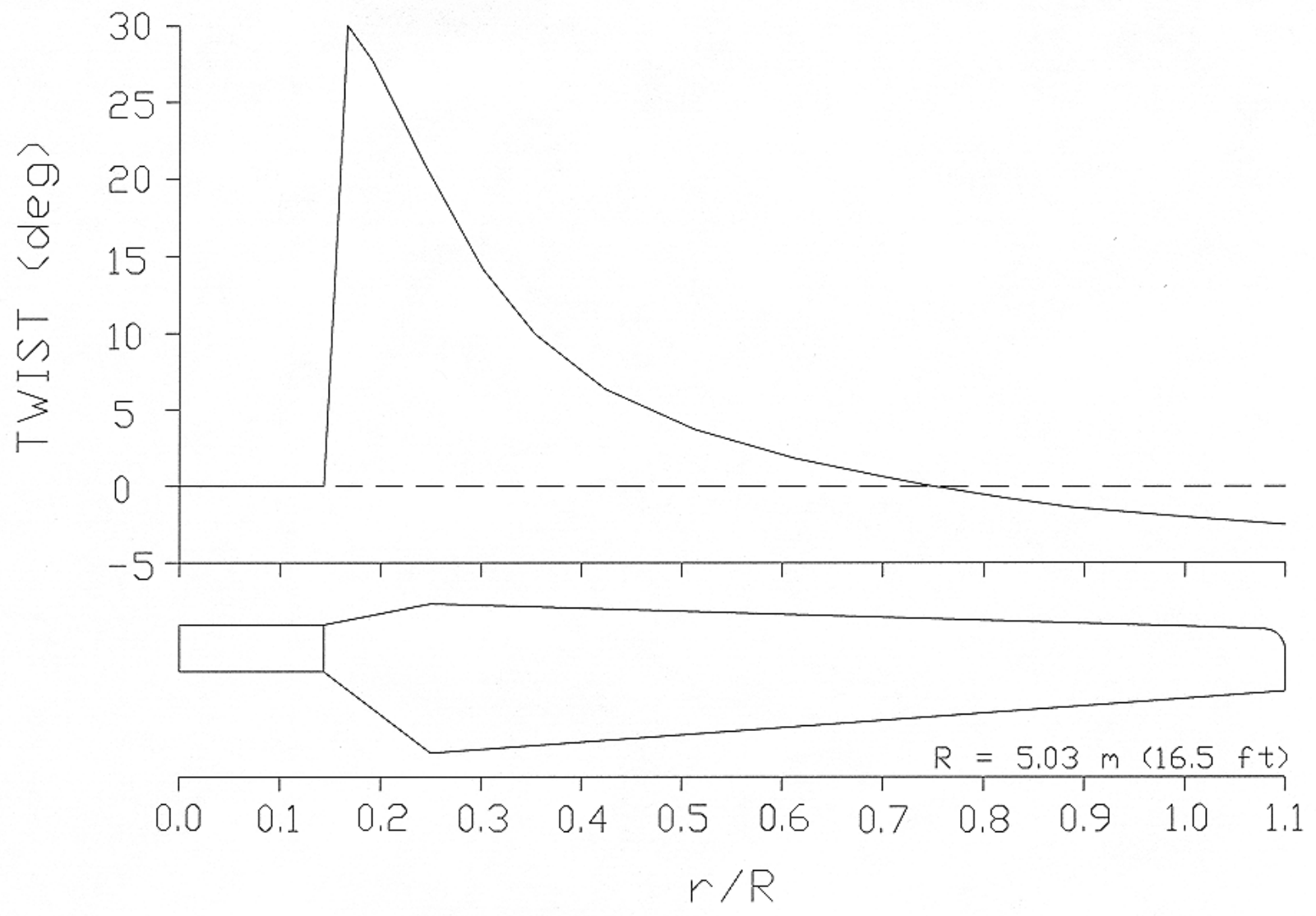

Fig.3: Final twist distribution of the tapered/twisted CER blade with pitch defined at $75 \%$ span of the baseline blade (the normalized chord is $\mathrm{c} / \mathrm{R}$ and the normalized radial position is $\mathrm{r} / \mathrm{R}$ ) 


\section{Performance Predictions}

The power curve of the baseline tapered/twisted CER blade is shown in Figure 4a. As indicated in this figure, the baseline blade in a two-bladed rotor configuration can greatly benefit from a $15 \%$ increase in rotor speed ( 83 instead of $72 \mathrm{rpm}$ ). Figure $4 \mathrm{~b}$ depicts the power curve of the extended tapered/twisted CER blade with the baseline blade for comparison. This figure shows that the performance of the extended blades can be considerably improved if the rotor speed is increased from 72 to $78 \mathrm{rpm}(8 \%$ increase). Also, increasing the blade pitch from 5 to 8 degrees provides the rated power of $20 \mathrm{~kW}$.

a)

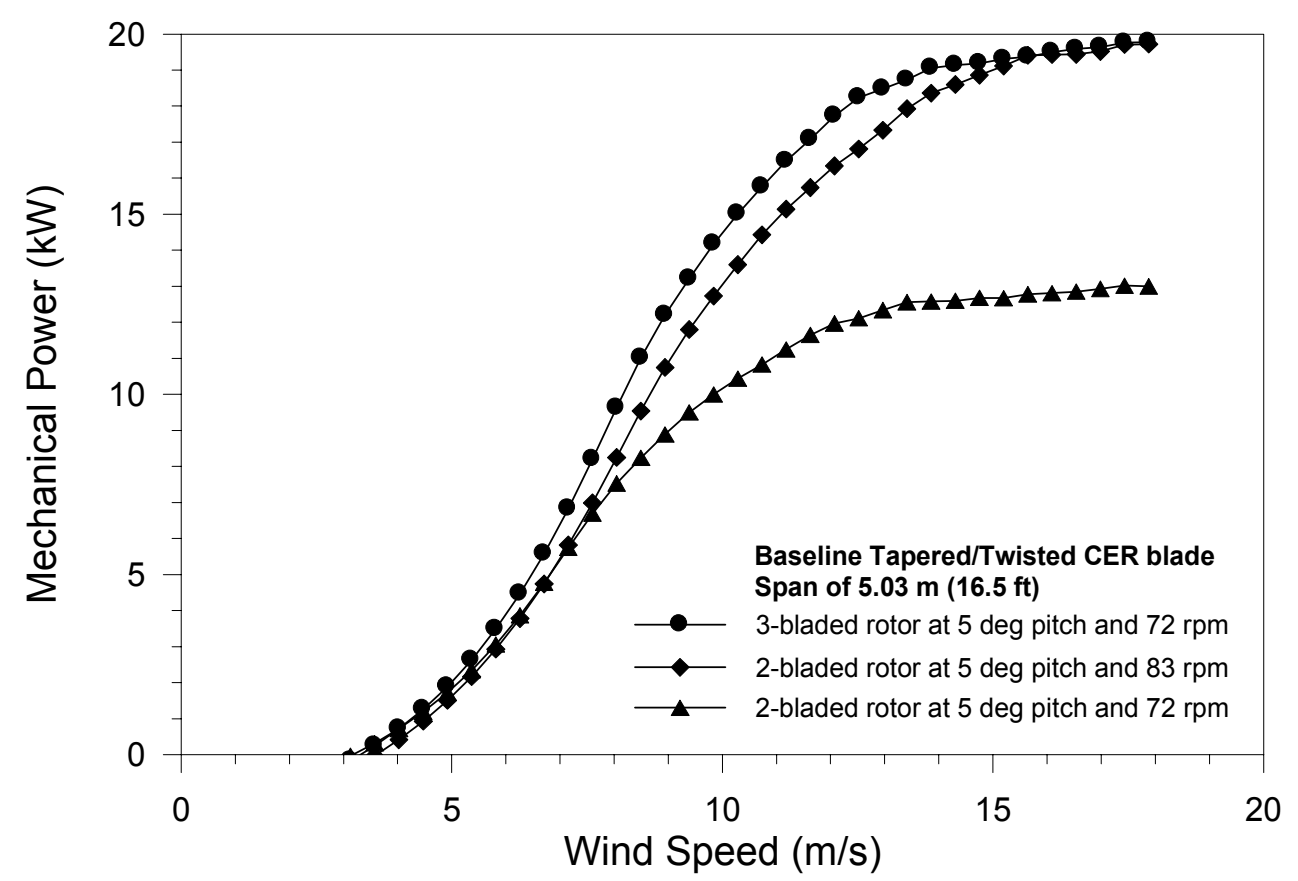

b)

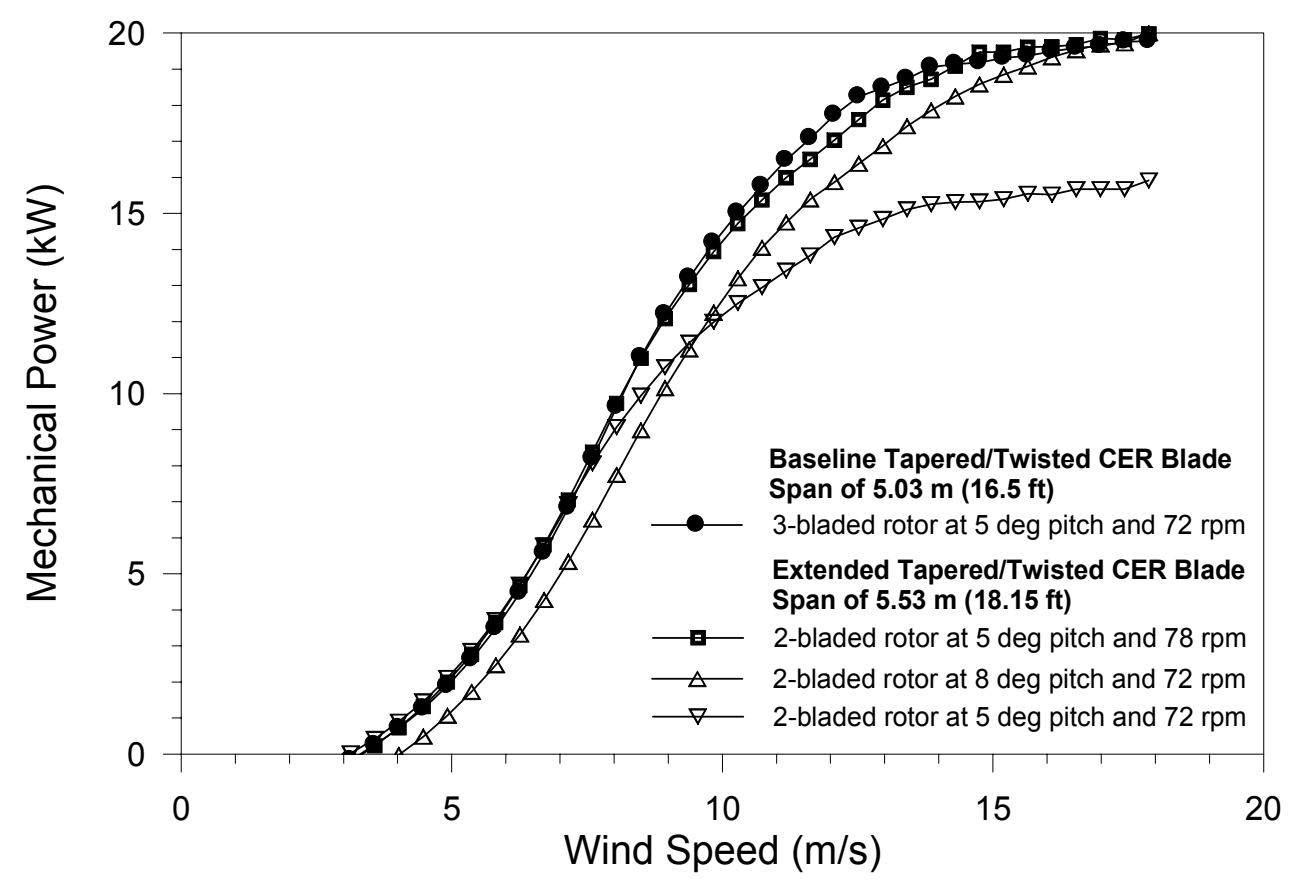

Fig. 4: Power curves for the tapered/twisted CER blade (mechanical power): a) baseline blade, b) extended blade The rotor thrust as a function of wind speed is shown in Figure 5. As expected, having two blades instead 
of three reduced the overall rotor thrust loads.

a)

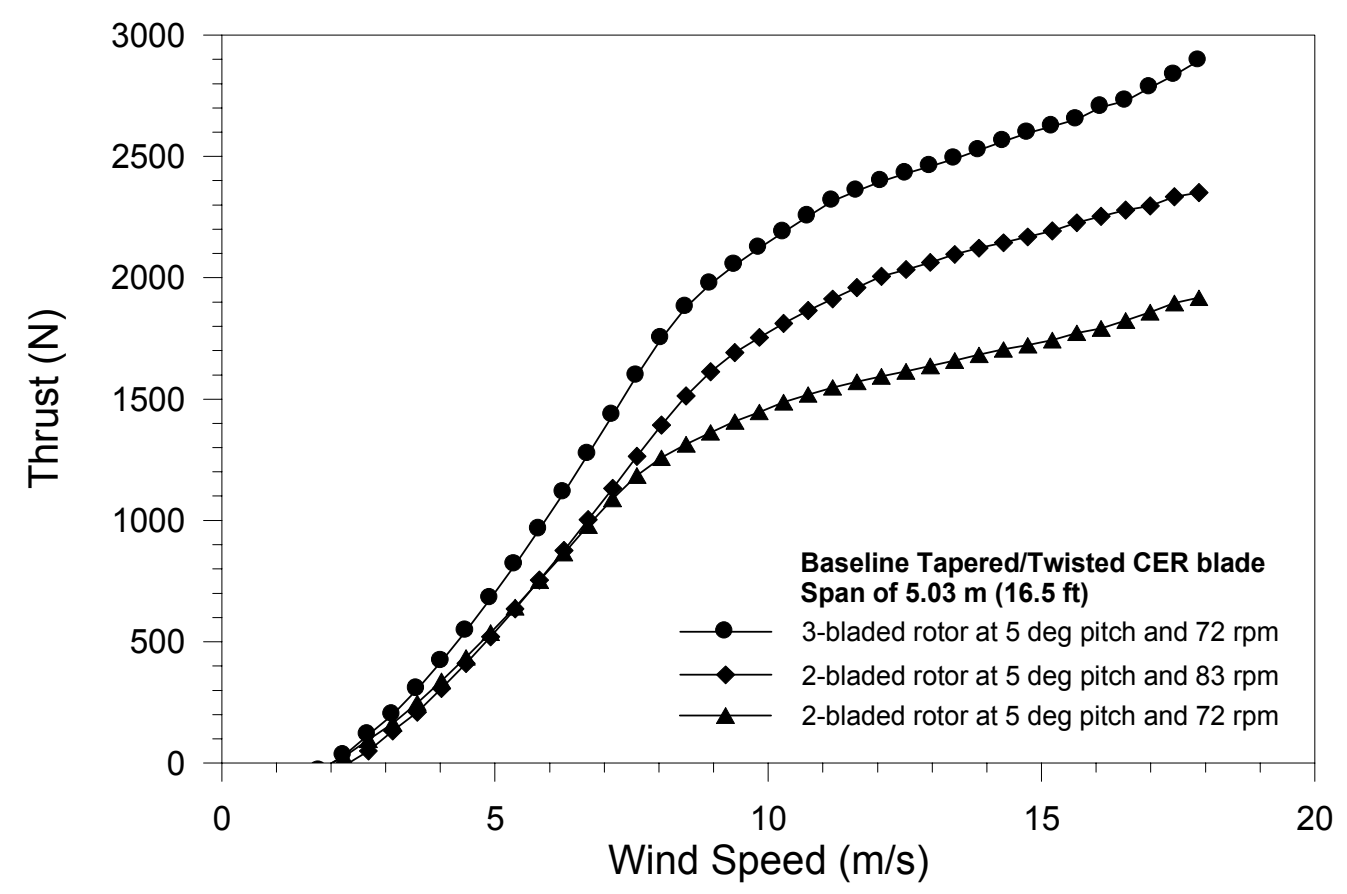

b)

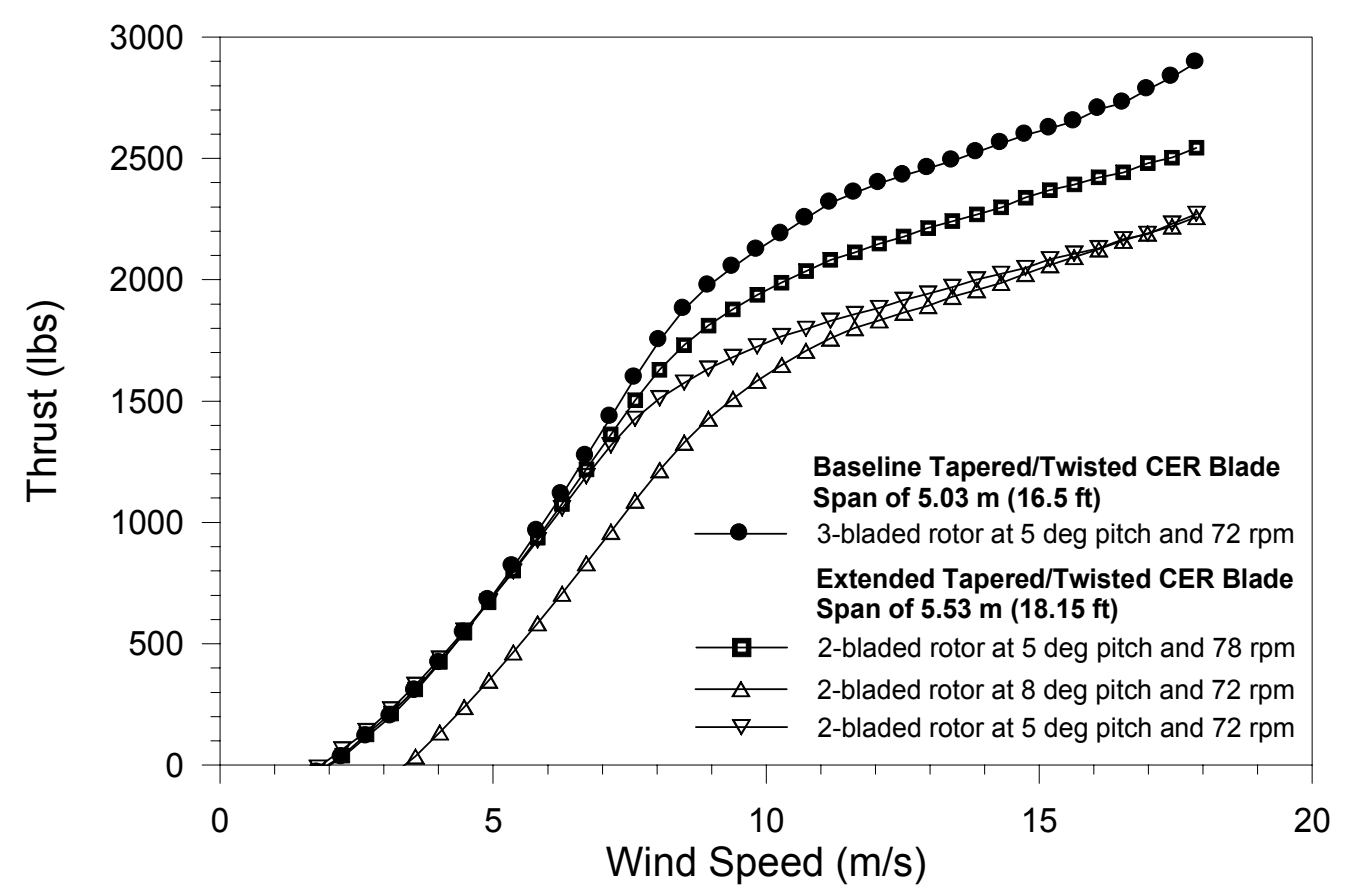

Fig. 5: Rotor thrust curves for the tapered/twisted CER blade: a) baseline blade, b) extended blade Figures 6 and 7 show the lift coefficient and axial inflow distributions, respectively, for four wind speeds: 
4.5, 6.7, 9.0, and $11.2 \mathrm{~m} / \mathrm{s}(10,15,20$, and $25 \mathrm{mph})$. Note that the inboard drop in lift coefficient shown in Figure $6 \mathrm{~b}$ for a wind speed of $11.2 \mathrm{~m} / \mathrm{s}(25 \mathrm{mph})$ indicates that the blade is stalled over that portion of the blade. The axial inflow distribution not being at the optimum value of one third is an indication that the new CER blades are not truly optimized for maximum energy capture. Also, the lower values of the axial induction coefficient for the extended blade for a given wind speed and radial position along the blade span, accounts for the lower thrust of the two-bladed rotor configuration.

a)

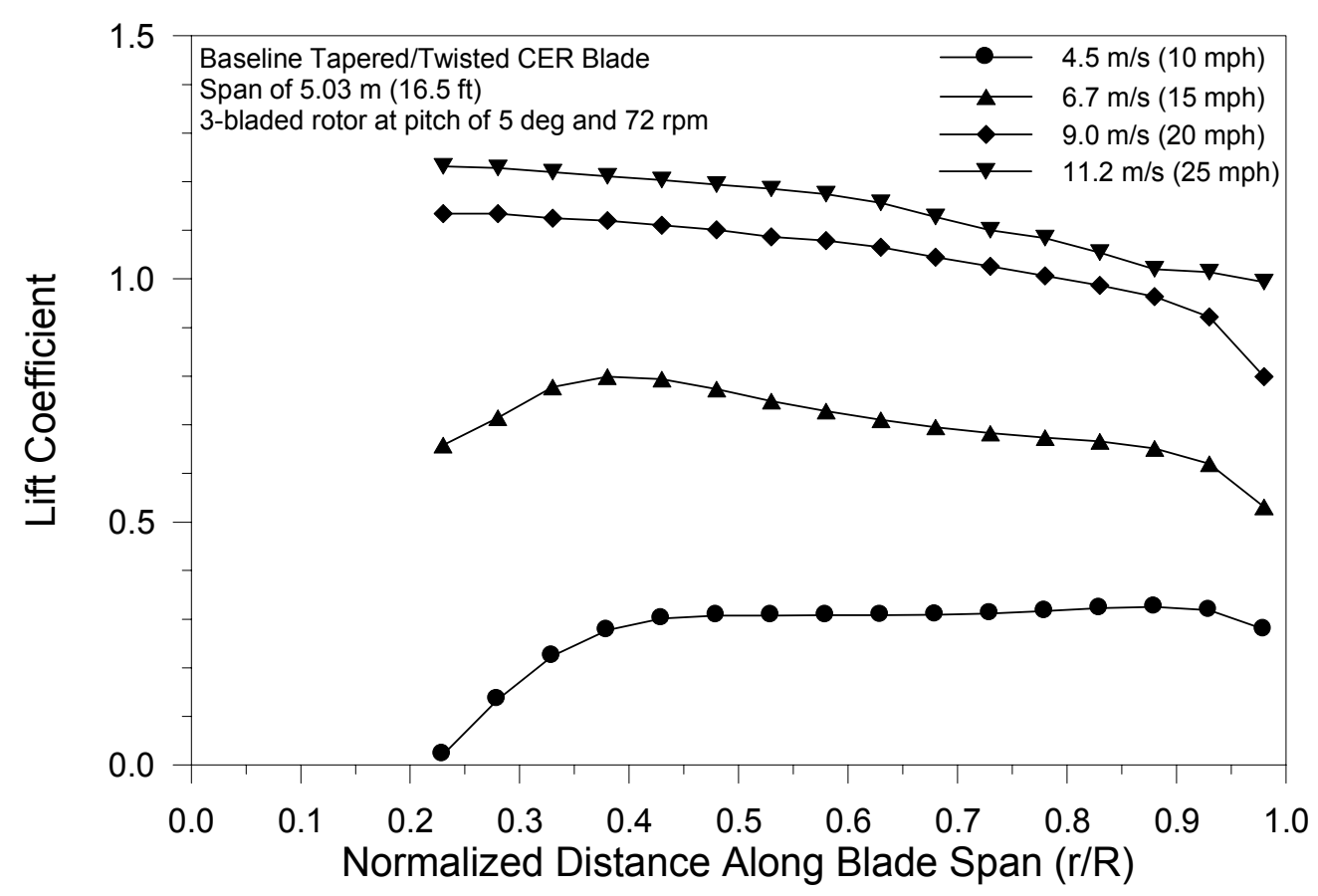

b)

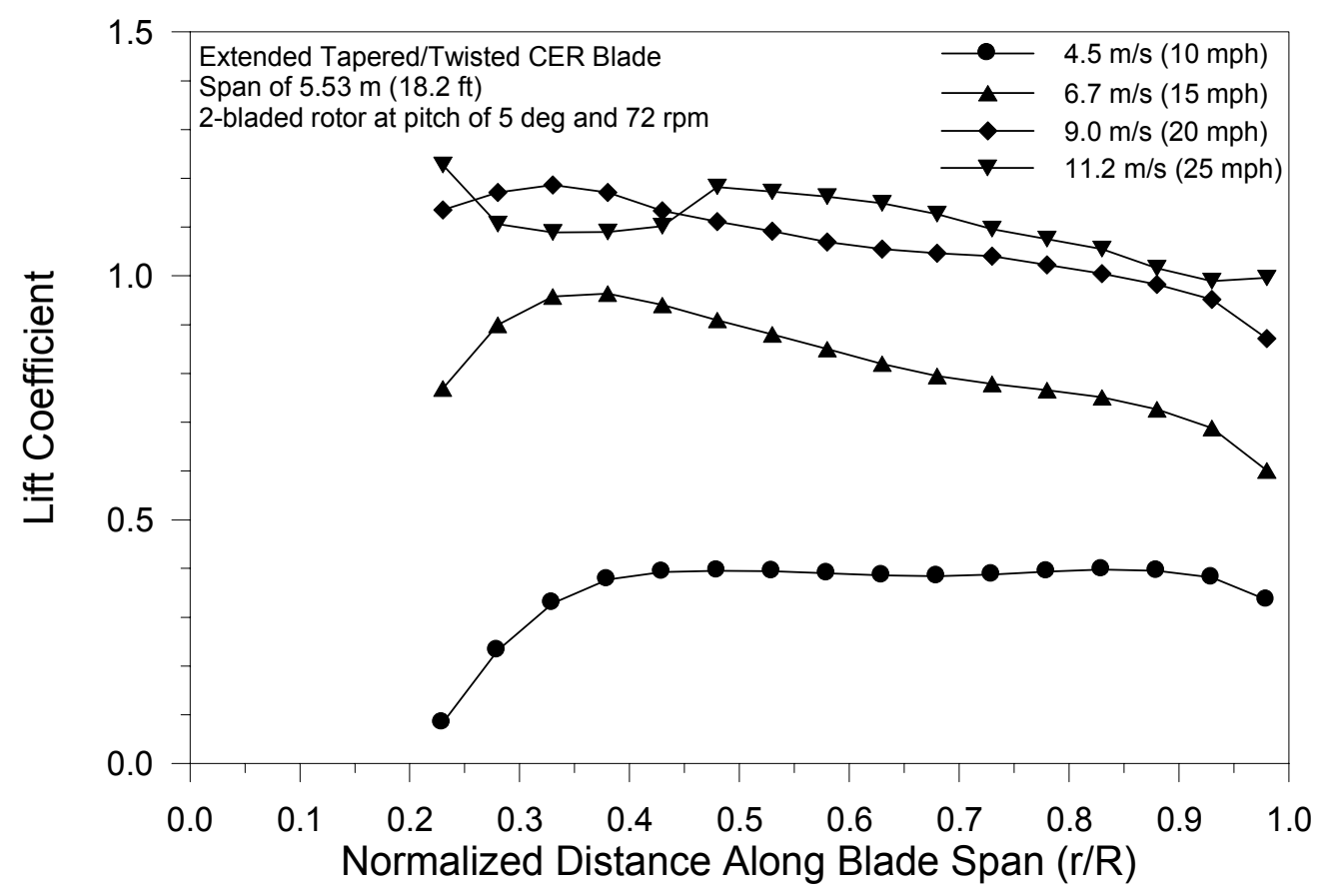

Fig. 6: Lift coefficient distribution along the span for the tapered/twisted CER blade: a) baseline blade, b) extended blade 
a)

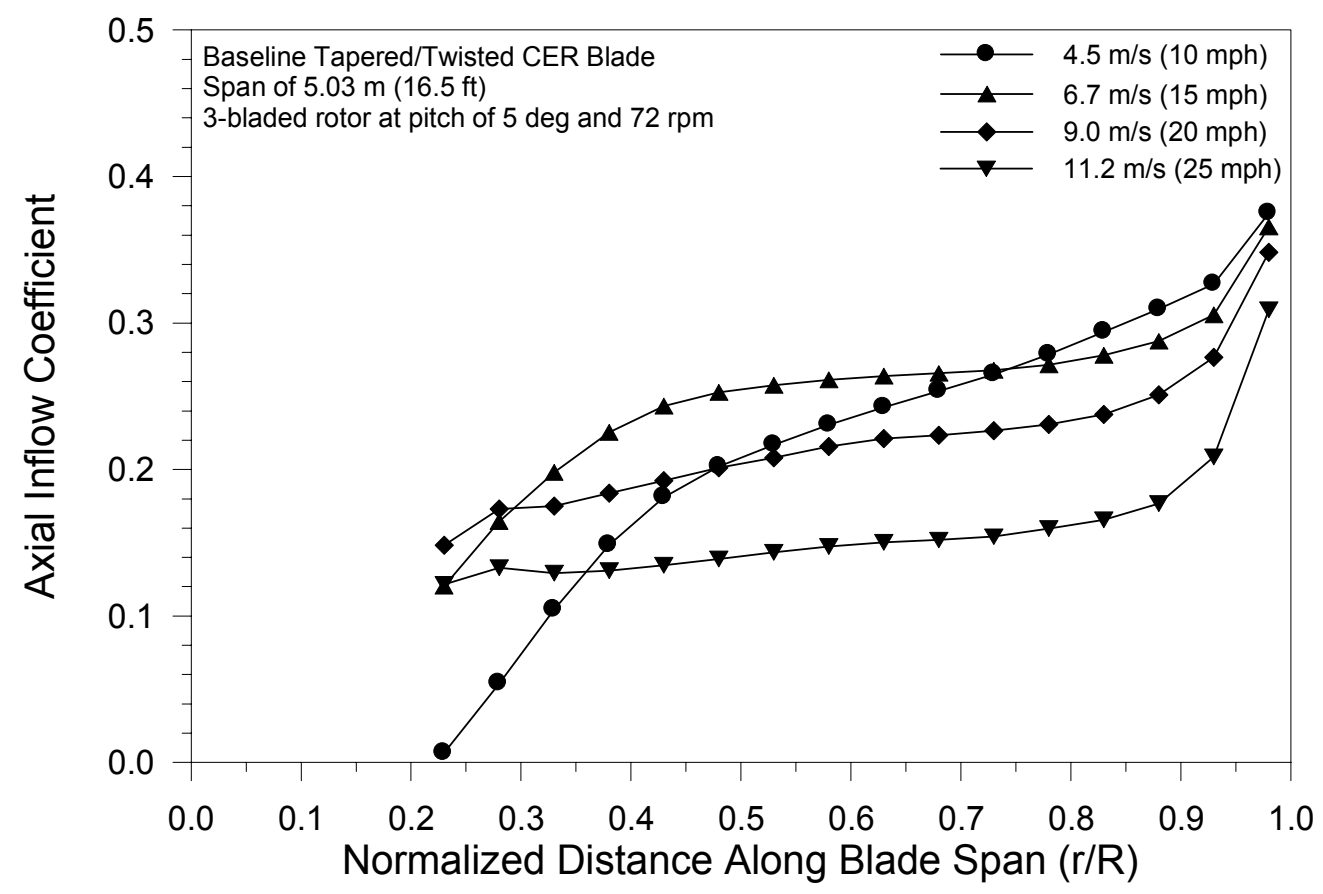

b)

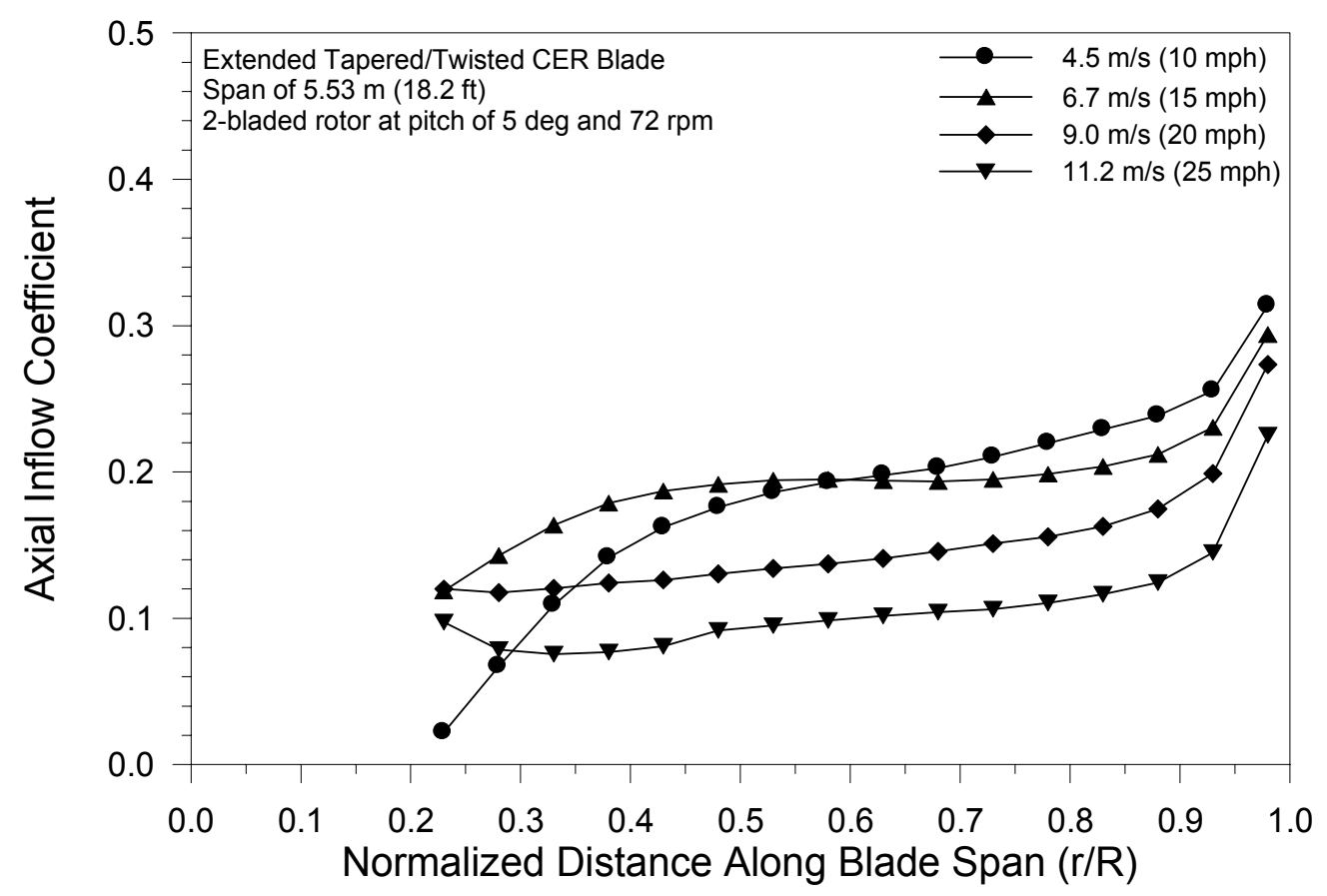

Fig. 7: Axial inflow coefficient distribution along the span for the tapered/twisted CER blade: a) baseline blade, b) extended blade 
Although the new blades were designed for constant-speed operation, performance under variable-speed conditions was also investigated because of plans to use them on the NREL variable-speed test bed. Figure 8 shows how the power coefficient varies with tip-speed ratio for different pitch settings and blade spans. Blade pitch angles of 0 to 7 degrees were considered but for clarity, only the results of pitch angles of $1,3,5$, and 7 degrees are shown. For the blade spans, results for shorter blades were computed to match different rated power requirements. All data presented in Figures 4-8 are tabulated in Appendix B.

a)

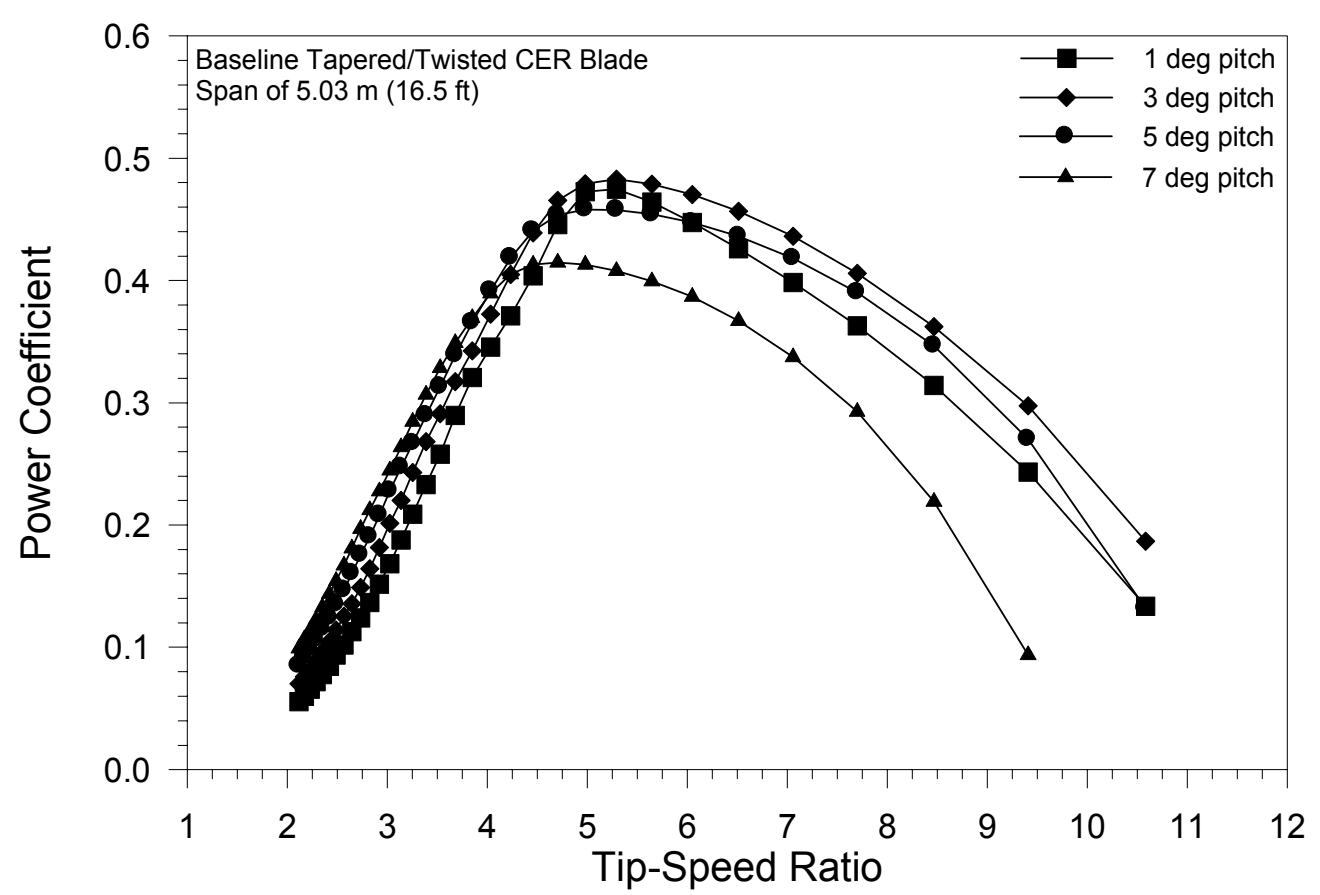

b)

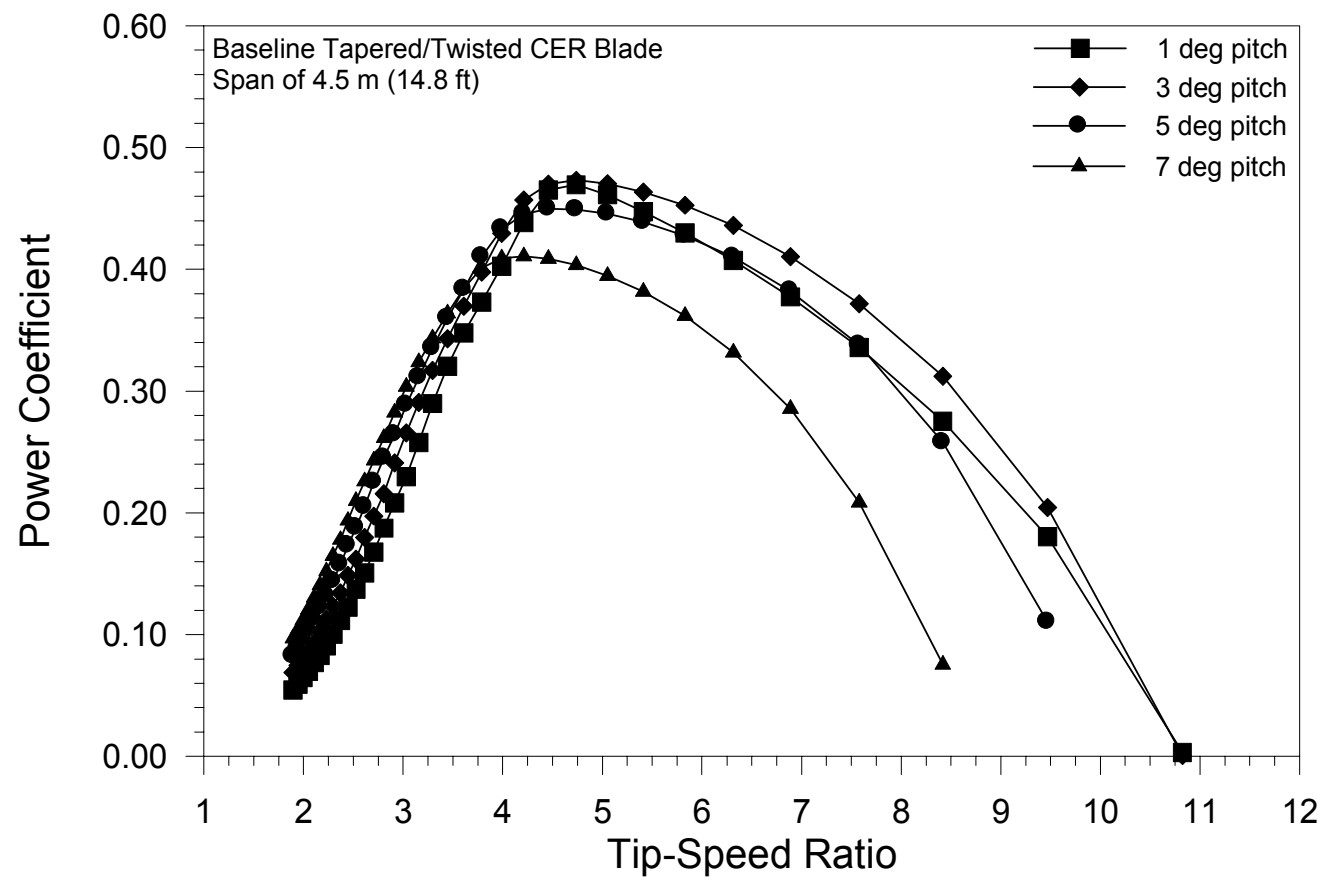

Fig. 8: Power coefficient vs. tip-speed ratio for the tapered/twisted CER blade: a) baseline blade, b) blade span of $4.5 \mathrm{~m}(14.8 \mathrm{ft}), \mathrm{c})$ blade span of $4.0 \mathrm{~m}(13.1 \mathrm{ft})$ 
c)

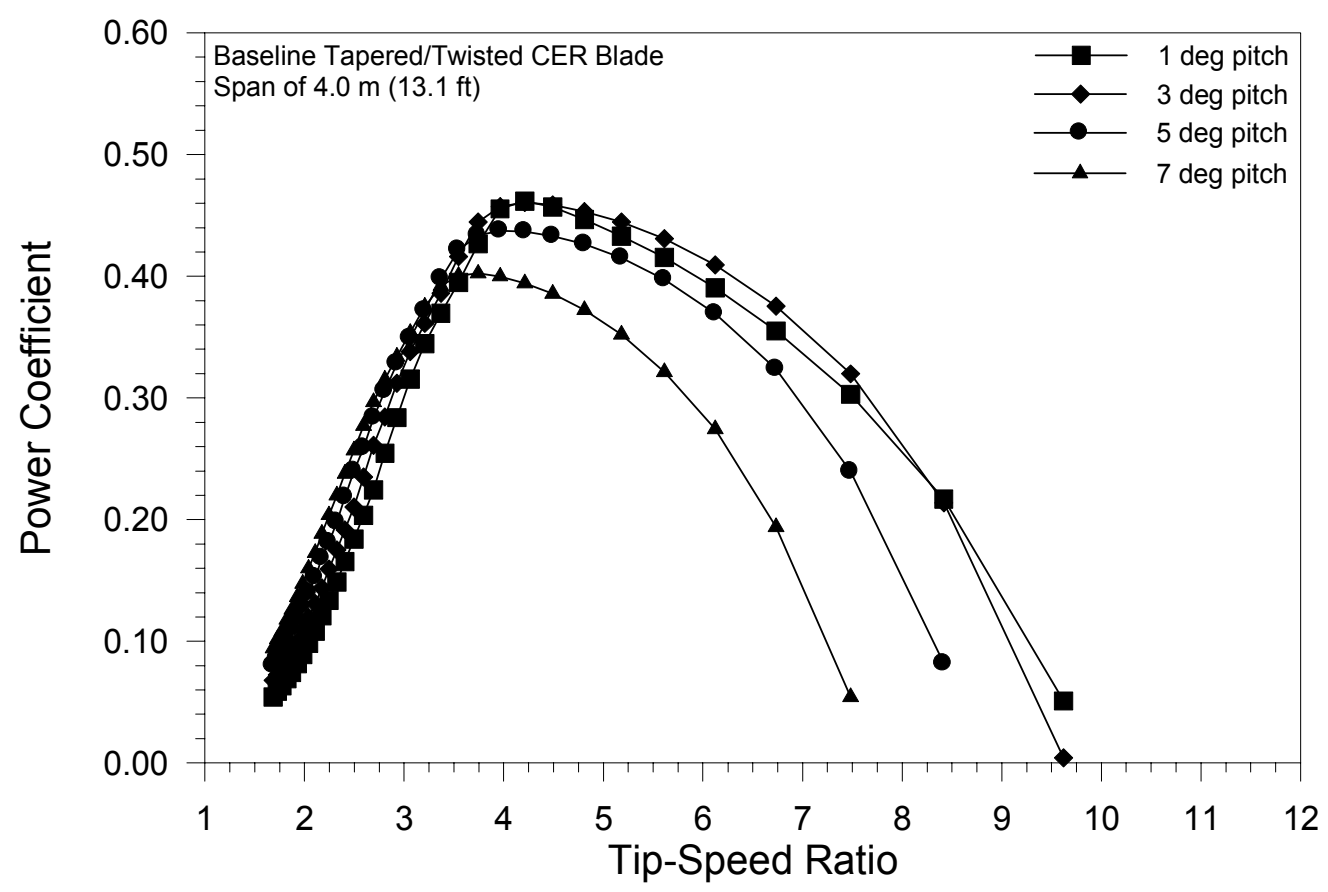

Fig. 8 (concluded) 


\section{Conclusions and Recommendations}

A third blade set for the CER was designed based on an extensive trade-off study that was conducted to determine the effect of several design constraints on rotor performance. The results of this study led to the design of a blade having a linear taper and a non linear twist distribution that makes use of the S809 airfoil from root to tip. This blade configuration is the logical continuation of the previous blade sets and will facilitate comparison with those earlier blades. Even though the new blades were designed with many constraints based on scientific needs, the new blades are more representative of commercial blades than the previous blades. The new blades were designed to be applicable for three- and two-bladed rotor configurations. To enhance performance in a two-bladed rotor configuration, extending the blade span by $10 \%$ and increasing the rotor speed from 72 to $78 \mathrm{rpm}$ were found to be beneficial. In fabricating the blades, it is recommended to use a mold with a length of $110 \%$ of the span of the baseline blade to accommodate both the baseline and extended blades. Although the new blades were designed for constant-speed operations, they can also be applicable for fundamental research in variable-speed operations. In the event that a fourth blade set for the CER would be built with the goal of designing a blade representative of commercial blades, the use of a more suitable root airfoil is strongly recommended. In this respect the S823/S822 airfoil combination would provide enhanced energy capture as compared with the S814/S809 combination. 


\section{References}

${ }^{1}$ Huyer, S.A., Simms, D., and Robinson, M.C., "Unsteady Aerodynamics Associated with a Horizontal-Axis Wind Turbine," AIAA Journal, Vol. 34, No. 7, 1996, pp. 1410-1419.

${ }^{2}$ Butterfield, C.P., Musial, W.P., and Simms, D.A., "Combined Experiment Phase I, Final Report," NREL/TP-257-4655, October 1996.

${ }^{3}$ Miller, M.S., Shipley, D.E., Young, T.S., Robinson, M.C., and Luttges, M.W., "Combined Experiment, Phase II Data Characterization,” NREL/TP-442-6916, November 1995.

${ }^{4}$ Simms, D.A., "Design of an Optimized Tapered and Twisted Blade for NREL's Unsteady Aerodynamics Experiment Grumman Wind Turbine," Appendix A of the Statement of Work of NREL Subcontract No. XAF-4-14076-03, September 20, 1996.

${ }^{5}$ Tangler, J.L. and Somers, D.S., "NREL Airfoil Families for HAWTs," American Wind Energy Association WindPower '95 Conference, Washington, DC, 1995.

${ }^{6}$ Selig, M.S. and Tangler, J.L., "Development and Application of a Multipoint Inverse Design Method for Horizontal Axis Wind Turbines," Wind Engineering, Vol. 19, No. 2, 1995, pp. 91-105.

${ }^{7}$ Giguère, P. and Selig, M.S., "Aerodynamic Blade Design Methods for Horizontal Axis Wind Turbines," $13^{\text {th }}$ Canadian Wind Energy Association Conference and Exhibition, Quebec City, Quebec, Canada, October 19-22, 1997.

${ }^{8}$ Selig, M.S. and Coverstone-Carroll, V.L., "Application of a Genetic Algorithm to Wind Turbine Design,” ASME Journal of Solar Energy Engineering, Vol. 118, March 1996, pp. 22-28.

${ }^{9}$ Hibb, B. and Radkey, R.L., "Calculating Rotor Performance with the Revised PROP Computer Code," Horizontal-Axis Wind System Rotor Performance Model Comparison-A Compendium, Wind Energy Research Center, Rockwell International, Rocky Flats Plant, Golden, CO, RFP-3508, UC-60, 1983.

${ }^{10}$ Corrigan, J.J. and Schilling, J.J., "Empirical Model for Stall Delay Due to Rotation," American Helicopter Society Aeromechanics Specialists Conference, San Francisco, CA, January 19-21, 1994.

${ }^{11}$ Tangler, J.L. and Selig, M.S., "An Evaluation of an Empirical Model for Stall Delay Due to Rotation for HAWTs," American Wind Energy Association WindPower '97 Conference, Austin, TX, 1997.

${ }^{12}$ Somers, D.M., "Design and Experimental Results for the S809 Airfoil," NREL/SR-440-6918, January 1997 (tests conducted in 1986).

${ }^{13}$ Somers, D.M., "Design and Experimental Results for the S814 Airfoil," NREL/SR-440-6919, January 1997 (tests conducted in 1994).

${ }^{14}$ Selig, M.S., Guglielmo, J.J., Broeren, A.P., and Giguère, P., Summary of Low Speed Airfoil DataVol. 1, SoarTech Publications, 1504 N. Horseshoe Circle, Virginia Beach, Virginia 23451, 1995.

${ }^{15}$ Selig, M.S., Lyon, C.A., Giguère, P, Ninham, C.P., and Guglielmo, J.J., Summary of Low Speed Airfoil Data-Vol. 2, SoarTech Publications, 1504 N. Horseshoe Circle, Virginia Beach, Virginia 23451, 1996. 


\section{Appendix A: Tabulated Data for the Tapered/Twisted CER blade}

\begin{tabular}{|c|c|c|c|c|}
\hline $\begin{array}{c}\text { Radial } \\
\text { Distance } \\
(\mathrm{m})\end{array}$ & $\begin{array}{c}\text { Radial } \\
\text { Distance } \\
\text { (in.) }\end{array}$ & Chord & Chord & Twist \\
\hline 0.000 & 0.000 & Hub diameter & Hub diameter & (degree) \\
\hline 0.724 & 28.500 & Hub diameter $^{3}$ & Hub diameter & 0.00 \\
\hline 0.838 & 33.000 & To be computed $^{3}$ & To be computed $^{3}$ & 30.00 \\
\hline 0.968 & 38.115 & To be computed $^{3}$ & To be computed $^{3}$ & 27.59 \\
\hline 1.258 & 49.500 & 0.737 & 29.000 & 20.05 \\
\hline 1.522 & 59.895 & 0.710 & 27.949 & 14.04 \\
\hline 1.798 & 70.785 & 0.682 & 26.849 & 9.67 \\
\hline 2.075 & 81.675 & 0.654 & 25.749 & 6.75 \\
\hline 2.352 & 92.565 & 0.626 & 24.650 & 4.84 \\
\hline 2.628 & 103.445 & 0.598 & 23.550 & 3.48 \\
\hline 2.905 & 114.345 & 0.570 & 22.450 & 2.40 \\
\hline 3.181 & 125.235 & 0.542 & 21.350 & 1.51 \\
\hline 3.458 & 136.125 & 0.514 & 20.250 & 0.76 \\
\hline 3.735 & 147.015 & 0.486 & 19.150 & 0.09 \\
\hline 2.772 & 148.496 & 0.483 & 19.000 & 0.00 \\
\hline 4.011 & 157.905 & 0.459 & 18.050 & -0.55 \\
\hline 4.288 & 168.795 & 0.431 & 16.950 & -1.11 \\
\hline 4.565 & 179.685 & 0.403 & 15.850 & -1.55 \\
\hline 4.841 & 190.575 & 0.375 & 14.751 & -1.84 \\
\hline 5.030 & 198.000 & 0.356 & 14.000 & -2.00 \\
\hline 5.118 & 201.465 & 0.347 & 13.651 & -2.08 \\
\hline 5.395 & 212.335 & 0.319 & 12.551 & -2.36 \\
\hline 5.533 & 217.800 & 0.305 & 12.000 & -2.50 \\
\hline & & & & \\
\hline
\end{tabular}

Notes:

1) A blade span of $5.030 \mathrm{~m}$ (198.0 in) corresponds to the baseline blade, whereas a span of $5.533 \mathrm{~m}$ (217.8 in.) corresponds to the extended blade.

2) The blade uses the $\mathrm{S} 809$ airfoil from root to tip.

3) The hub extends to the 28.5-in. station. From the 28.5-in. to the 49.5-in station, there is a linear transition from the hub to the S809 airfoil. The chord lengths in that region can be computed using the following equation according to the hub diameter.

$$
c=\left[\frac{29-H D}{21}\right] r+2.357 H D-39.357
$$

where $c$ is the chord in inches, $H D$ is the hub diameter in inches, and $r$ is the radial distance in inches as well.

4) The pitch is defined at the $75 \%$ blade station and the pitch axis is the $30 \%$ chord line. A pitch setting of 5 degrees is recommended for both the two- and three-blade rotors. Note that the twist at the $75 \%$ station is zero only in the case of the three-blade rotor. 
Appendix B: Tabulated Results Figures. 4-8

\begin{tabular}{|c|c|c|c|c|c|c|c|}
\hline \multicolumn{2}{|c|}{ Data shown in Fig. 4} & \multicolumn{3}{|c|}{ Baseline Blade } & \multicolumn{3}{|c|}{ Extended Blade } \\
\hline & rotor & 3-bladed & 2-bladed & 2-bladed & 2-bladed & 2-bladed & 2-bladed \\
\hline & Pitch (degree) & 5 & 5 & 5 & 5 & 5 & 8 \\
\hline & rpm & 72 & 72 & 83 & 72 & 78 & 72 \\
\hline $\begin{array}{l}\text { Wind } \\
\text { Speed } \\
(\mathrm{m} / \mathrm{s})\end{array}$ & $\begin{array}{l}\text { Wind } \\
\text { Speed } \\
(\mathrm{mph})\end{array}$ & \begin{tabular}{|c|} 
Mechanical \\
Power \\
$(\mathrm{kW})$
\end{tabular} & $\begin{array}{c}\text { Mechanical } \\
\text { Power } \\
(\mathrm{kW})\end{array}$ & $\begin{array}{c}\text { Mechanical } \\
\text { Power } \\
(\mathrm{kW})\end{array}$ & $\begin{array}{c}\text { Mechanical } \\
\text { Power } \\
(\mathrm{kW})\end{array}$ & $\begin{array}{c}\text { Mechanical } \\
\text { Power } \\
(\mathrm{kW})\end{array}$ & $\begin{array}{c}\text { Mechanical } \\
\text { Power } \\
(\mathrm{kW})\end{array}$ \\
\hline 0.4 & 1.0 & -2.93 & -2.17 & -3.27 & -2.16 & -2.62 & -6.70 \\
\hline 0.9 & 2.0 & -2.16 & -1.62 & -2.48 & -1.92 & -2.36 & -4.92 \\
\hline 1.3 & 3.0 & -1.62 & -1.40 & -2.19 & -1.37 & -1.72 & -3.53 \\
\hline 1.8 & 4.0 & -1.37 & -0.98 & -1.58 & -0.98 & -1.47 & -2.49 \\
\hline 2.2 & 5.0 & -0.93 & -0.65 & -1.29 & -0.72 & -0.98 & -1.89 \\
\hline 2.7 & 6.0 & -0.62 & -0.39 & -0.82 & -0.36 & -0.67 & -1.31 \\
\hline 3.1 & 7.0 & -0.17 & -0.03 & -0.49 & 0.02 & -0.22 & -0.90 \\
\hline 3.6 & 8.0 & 0.25 & 0.32 & -0.03 & 0.42 & 0.23 & -0.48 \\
\hline 4.0 & 9.0 & 0.72 & 0.72 & 0.42 & 0.90 & 0.73 & -0.02 \\
\hline 4.5 & 10.0 & 1.26 & 1.19 & 0.93 & 1.46 & 1.32 & 0.49 \\
\hline 4.9 & 11.0 & 1.89 & 1.72 & 1.51 & 2.11 & 2.00 & 1.07 \\
\hline 5.4 & 12.0 & 2.63 & 2.34 & 2.17 & 2.86 & 2.77 & 1.73 \\
\hline 5.8 & 13.0 & 3.49 & 3.06 & 2.93 & 3.72 & 3.66 & 2.47 \\
\hline 6.3 & 14.0 & 4.47 & 3.87 & 3.78 & 4.70 & 4.67 & 3.32 \\
\hline 6.7 & 15.0 & 5.58 & 4.77 & 4.74 & 5.78 & 5.80 & 4.28 \\
\hline 7.2 & 16.0 & 6.83 & 5.74 & 5.82 & 6.93 & 7.05 & 5.34 \\
\hline 7.6 & 17.0 & 8.20 & 6.69 & 6.99 & 8.06 & 8.38 & 6.51 \\
\hline 8.0 & 18.0 & 9.63 & 7.53 & 8.25 & 9.07 & 9.73 & 7.75 \\
\hline 8.5 & 19.0 & 11.01 & 8.24 & 9.54 & 9.94 & 10.98 & 8.99 \\
\hline 8.9 & 20.0 & 12.20 & 8.89 & 10.75 & 10.73 & 12.08 & 10.16 \\
\hline 9.4 & 21.0 & 13.21 & 9.50 & 11.80 & 11.41 & 13.03 & 11.23 \\
\hline 9.8 & 22.0 & 14.18 & 10.00 & 12.73 & 11.99 & 13.94 & 12.25 \\
\hline 10.3 & 23.0 & 15.01 & 10.44 & 13.60 & 12.51 & 14.72 & 13.20 \\
\hline 10.7 & 24.0 & 15.76 & 10.83 & 14.43 & 12.95 & 15.37 & 14.05 \\
\hline 11.2 & 25.0 & 16.48 & 11.25 & 15.14 & 13.41 & 15.99 & 14.75 \\
\hline 11.6 & 26.0 & 17.08 & 11.65 & 15.74 & 13.83 & 16.50 & 15.39 \\
\hline 12.1 & 27.0 & 17.73 & 11.97 & 16.34 & 14.34 & 17.03 & 15.87 \\
\hline 12.5 & 28.0 & 18.24 & 12.11 & 16.81 & 14.60 & 17.60 & 16.38 \\
\hline 13.0 & 29.0 & 18.48 & 12.34 & 17.33 & 14.84 & 18.14 & 16.87 \\
\hline 13.4 & 30.0 & 18.73 & 12.56 & 17.93 & 15.11 & 18.50 & 17.42 \\
\hline 13.9 & 31.0 & 19.06 & 12.58 & 18.36 & 15.25 & 18.72 & 17.86 \\
\hline 14.3 & 32.0 & 19.14 & 12.60 & 18.60 & 15.31 & 19.09 & 18.25 \\
\hline 14.8 & 33.0 & 19.19 & 12.68 & 18.86 & 15.33 & 19.47 & 18.58 \\
\hline 15.2 & 34.0 & 19.31 & 12.67 & 19.11 & 15.39 & 19.47 & 18.85 \\
\hline 15.6 & 35.0 & 19.37 & 12.78 & 19.41 & 15.54 & 19.61 & 19.08 \\
\hline 16.1 & 36.0 & 19.50 & 12.81 & 19.43 & 15.52 & 19.62 & 19.33 \\
\hline 16.5 & 37.0 & 19.59 & 12.85 & 19.44 & 15.67 & 19.68 & 19.53 \\
\hline 17.0 & 38.0 & 19.64 & 12.93 & 19.52 & 15.67 & 19.85 & 19.69 \\
\hline 17.4 & 39.0 & 19.76 & 13.02 & 19.71 & 15.67 & 19.82 & 19.72 \\
\hline 17.9 & 40.0 & 19.78 & 13.00 & 19.72 & 15.91 & 19.98 & 20.00 \\
\hline
\end{tabular}




\begin{tabular}{|c|c|c|c|c|c|c|c|}
\hline \multicolumn{2}{|c|}{ Data shown in Fig. 5} & \multicolumn{3}{|c|}{ Baseline Blade } & \multicolumn{3}{|c|}{ Extended Blade } \\
\hline & rotor & 3-bladed & 2-bladed & 2-bladed & 2-bladed & 2-bladed & 2-bladed \\
\hline & ch (degree) & 5 & 5 & 5 & 5 & 5 & 8 \\
\hline & rpm & 72 & 72 & 83 & 72 & 78 & 72 \\
\hline $\begin{array}{l}\text { Wind } \\
\text { Speed } \\
(\mathrm{m} / \mathrm{s})\end{array}$ & $\begin{array}{l}\text { Wind } \\
\text { Speed } \\
(\mathrm{mph})\end{array}$ & $\begin{array}{l}\text { Thrust } \\
\text { (N) }\end{array}$ & $\begin{array}{l}\text { Thrust } \\
\text { (N) }\end{array}$ & $\begin{array}{c}\text { Thrust } \\
\text { (N) }\end{array}$ & $\begin{array}{l}\text { Thrust } \\
\text { (N) }\end{array}$ & $\begin{array}{l}\text { Thrust } \\
\text { (N) }\end{array}$ & $\begin{array}{l}\text { Thrust } \\
\text { (N) }\end{array}$ \\
\hline 0.4 & 1.0 & -174.40 & -139.95 & -197.05 & -151.53 & -187.27 & -316.51 \\
\hline 0.9 & 2.0 & -140.79 & -114.22 & -171.62 & -105.42 & -137.28 & -302.02 \\
\hline 1.3 & 3.0 & -98.17 & -68.58 & -121.23 & -63.97 & -94.65 & -276.98 \\
\hline 1.8 & 4.0 & -31.47 & -26.60 & -79.14 & -10.90 & -26.21 & -240.07 \\
\hline 2.2 & 5.0 & 31.13 & 25.30 & -12.56 & 64.30 & 38.32 & -176.30 \\
\hline 2.7 & 6.0 & 116.80 & 95.32 & 49.00 & 139.19 & 126.57 & -116.48 \\
\hline 3.1 & 7.0 & 199.42 & 163.30 & 132.00 & 228.33 & 212.38 & -47.20 \\
\hline 3.6 & 8.0 & 305.12 & 247.70 & 209.67 & 329.76 & 312.49 & 35.96 \\
\hline 4.0 & 9.0 & 419.97 & 338.58 & 306.82 & 438.13 & 425.09 & 134.66 \\
\hline 4.5 & 10.0 & 544.28 & 435.49 & 410.57 & 552.91 & 545.17 & 239.34 \\
\hline 4.9 & 11.0 & 678.13 & 537.14 & 520.01 & 672.96 & 670.98 & 348.82 \\
\hline 5.4 & 12.0 & 817.56 & 642.39 & 634.81 & 797.32 & 801.70 & 464.82 \\
\hline 5.8 & 13.0 & 962.96 & 751.66 & 753.57 & 925.89 & 936.69 & 584.38 \\
\hline 6.3 & 14.0 & 1114.77 & 864.02 & 875.99 & 1057.52 & 1075.94 & 706.77 \\
\hline 6.7 & 15.0 & 1272.10 & 978.08 & 1002.44 & 1190.15 & 1218.32 & 832.27 \\
\hline 7.2 & 16.0 & 1433.87 & 1088.37 & 1132.00 & 1317.00 & 1362.30 & 960.90 \\
\hline 7.6 & 17.0 & 1596.57 & 1184.66 & 1263.68 & 1426.19 & 1502.54 & 1090.22 \\
\hline 8.0 & 18.0 & 1750.40 & 1258.15 & 1393.38 & 1511.02 & 1629.54 & 1215.45 \\
\hline 8.5 & 19.0 & 1878.28 & 1313.71 & 1513.19 & 1575.69 & 1730.67 & 1329.31 \\
\hline 8.9 & 20.0 & 1974.14 & 1362.73 & 1612.86 & 1632.83 & 1811.01 & 1427.35 \\
\hline 9.4 & 21.0 & 2052.25 & 1407.05 & 1691.24 & 1680.91 & 1877.81 & 1509.57 \\
\hline 9.8 & 22.0 & 2123.21 & 1446.70 & 1753.81 & 1724.88 & 1936.85 & 1583.81 \\
\hline 10.3 & 23.0 & 2186.89 & 1486.94 & 1811.52 & 1766.84 & 1988.20 & 1649.02 \\
\hline 10.7 & 24.0 & 2252.14 & 1518.75 & 1865.11 & 1796.67 & 2035.03 & 1707.32 \\
\hline 11.2 & 25.0 & 2316.49 & 1547.45 & 1912.35 & 1830.09 & 2081.27 & 1758.21 \\
\hline 11.6 & 26.0 & 2357.95 & 1571.14 & 1958.37 & 1857.17 & 2112.68 & 1801.20 \\
\hline 12.1 & 27.0 & 2397.56 & 1593.53 & 2005.18 & 1882.94 & 2148.12 & 1832.97 \\
\hline 12.5 & 28.0 & 2428.57 & 1613.76 & 2033.92 & 1915.76 & 2177.33 & 1864.80 \\
\hline 13.0 & 29.0 & 2459.73 & 1636.27 & 2063.24 & 1942.34 & 2212.58 & 1892.75 \\
\hline 13.4 & 30.0 & 2491.34 & 1658.64 & 2096.18 & 1969.43 & 2241.20 & 1930.09 \\
\hline 13.9 & 31.0 & 2525.39 & 1681.85 & 2121.63 & 1999.55 & 2268.02 & 1958.21 \\
\hline 14.3 & 32.0 & 2562.99 & 1704.49 & 2144.19 & 2023.80 & 2297.57 & 1987.11 \\
\hline 14.8 & 33.0 & 2597.83 & 1721.54 & 2167.99 & 2048.08 & 2338.15 & 2023.64 \\
\hline 15.2 & 34.0 & 2623.99 & 1742.41 & 2192.80 & 2083.93 & 2368.99 & 2060.49 \\
\hline 15.6 & 35.0 & 2653.13 & 1772.34 & 2226.45 & 2106.60 & 2392.15 & 2093.65 \\
\hline 16.1 & 36.0 & 2704.09 & 1790.50 & 2252.86 & 2129.19 & 2421.34 & 2125.09 \\
\hline 16.5 & 37.0 & 2729.91 & 1823.83 & 2277.96 & 2166.21 & 2442.97 & 2161.30 \\
\hline 17.0 & 38.0 & 2784.09 & 1857.73 & 2295.89 & 2188.42 & 2480.59 & 2191.03 \\
\hline 17.4 & 39.0 & 2836.14 & 1895.33 & 2333.48 & 2230.37 & 2503.90 & 2220.56 \\
\hline 17.9 & 40.0 & 2895.23 & 1917.64 & 2350.19 & 2270.95 & 2544.11 & 2258.30 \\
\hline
\end{tabular}




\begin{tabular}{|c|c|c|c|c|}
\hline \multicolumn{5}{|c|}{ Data shown in Fig. 6} \\
\hline \multicolumn{5}{|c|}{ Baseline Blade } \\
\hline \begin{tabular}{|c|} 
Normalized \\
Radial \\
Distance \\
$(\mathrm{r} / \mathrm{R})$
\end{tabular} & \begin{tabular}{|c|} 
Lift \\
Coefficient \\
Wind Speed \\
$4.5 \mathrm{~m} / \mathrm{s} ; 10 \mathrm{mph}$
\end{tabular} & \begin{tabular}{|c|} 
Lift \\
Coefficient \\
Wind Speed \\
$6.7 \mathrm{~m} / \mathrm{s} ; 15 \mathrm{mph}$
\end{tabular} & $\begin{array}{c}\text { Lift } \\
\text { Coefficient } \\
\text { Wind Speed } \\
8.9 \mathrm{~m} / \mathrm{s} ; 20 \mathrm{mph}\end{array}$ & \begin{tabular}{|c|} 
Lift \\
Coefficient \\
Wind Speed \\
$11.2 \mathrm{~m} / \mathrm{s} ; 25 \mathrm{mph}$
\end{tabular} \\
\hline 0.03 and 0.08 & 0 & 0 & 0 & 0 \\
\hline 0.13 & 0.2695 & 0.8077 & 1.1504 & 1.2206 \\
\hline 0.18 & 0.056 & 0.7449 & 1.1505 & 1.2397 \\
\hline 0.23 & 0.0221 & 0.6578 & 1.1342 & 1.2315 \\
\hline 0.28 & 0.1352 & 0.7147 & 1.1341 & 1.2283 \\
\hline 0.33 & 0.2243 & 0.7774 & 1.1249 & 1.2197 \\
\hline 0.38 & 0.2773 & 0.7991 & 1.12 & 1.2112 \\
\hline 0.43 & 0.3015 & 0.7937 & 1.1098 & 1.2027 \\
\hline 0.48 & 0.3077 & 0.7729 & 1.1005 & 1.1938 \\
\hline 0.53 & 0.3078 & 0.7488 & 1.0866 & 1.1849 \\
\hline 0.58 & 0.308 & 0.7281 & 1.0787 & 1.1739 \\
\hline 0.63 & 0.3083 & 0.7102 & 1.0651 & 1.1559 \\
\hline 0.68 & 0.3093 & 0.6949 & 1.0443 & 1.1275 \\
\hline 0.73 & 0.3117 & 0.6825 & 1.0255 & 1.0999 \\
\hline 0.78 & 0.3165 & 0.6734 & 1.0062 & 1.0838 \\
\hline 0.83 & 0.3224 & 0.6653 & 0.9861 & 1.0537 \\
\hline 0.88 & 0.3255 & 0.6512 & 0.9636 & 1.02 \\
\hline 0.93 & 0.3185 & 0.6193 & 0.9213 & 1.0137 \\
\hline 0.98 & 0.2787 & 0.5311 & 0.7986 & 0.9935 \\
\hline \multicolumn{5}{|c|}{ Extended Blade } \\
\hline $\begin{array}{c}\text { Normalized } \\
\text { Radial } \\
\text { Distance } \\
(\mathrm{r} / \mathrm{R}) \\
\end{array}$ & $\begin{array}{c}\text { Lift } \\
\text { Coefficient } \\
\text { Wind Speed } \\
4.5 \mathrm{~m} / \mathrm{s} ; 10 \mathrm{mph} \\
\end{array}$ & $\begin{array}{c}\text { Lift } \\
\text { Coefficient } \\
\text { Wind Speed } \\
6.7 \mathrm{~m} / \mathrm{s} ; 15 \mathrm{mph} \\
\end{array}$ & $\begin{array}{c}\text { Lift } \\
\text { Coefficient } \\
\text { Wind Speed } \\
8.9 \mathrm{~m} / \mathrm{s} ; 20 \mathrm{mph} \\
\end{array}$ & \begin{tabular}{|c|} 
Lift \\
Coefficient \\
Wind Speed \\
$11.2 \mathrm{~m} / \mathrm{s} ; 25 \mathrm{mph}$ \\
\end{tabular} \\
\hline 0.03 and 0.08 & 0 & 0 & 0 & 0 \\
\hline 0.13 & 0.2376 & 0.9928 & 1.2155 & 1.139 \\
\hline 0.18 & 0.007 & 0.7706 & 1.137 & 1.2309 \\
\hline 0.23 & 0.0838 & 0.769 & 1.1348 & 1.2277 \\
\hline 0.28 & 0.232 & 0.8995 & 1.1711 & 1.1056 \\
\hline 0.33 & 0.3292 & 0.9577 & 1.186 & 1.0889 \\
\hline 0.38 & 0.3774 & 0.9632 & 1.1704 & 1.0895 \\
\hline 0.43 & 0.3929 & 0.9401 & 1.1329 & 1.1021 \\
\hline 0.48 & 0.3953 & 0.9091 & 1.1114 & 1.1823 \\
\hline 0.53 & 0.3939 & 0.8799 & 1.0909 & 1.1722 \\
\hline 0.58 & 0.39 & 0.8494 & 1.0693 & 1.1624 \\
\hline 0.63 & 0.3856 & 0.8197 & 1.0551 & 1.149 \\
\hline 0.68 & 0.3838 & 0.795 & 1.0465 & 1.1262 \\
\hline 0.73 & 0.3873 & 0.7781 & 1.0399 & 1.0956 \\
\hline 0.78 & 0.3936 & 0.7654 & 1.0219 & 1.0752 \\
\hline 0.83 & 0.3978 & 0.7504 & 1.0041 & 1.0548 \\
\hline 0.88 & 0.3949 & 0.7266 & 0.9823 & 1.0156 \\
\hline 0.93 & 0.3812 & 0.688 & 0.9512 & 0.9892 \\
\hline 0.98 & 0.3356 & 0.6007 & 0.8709 & 0.9955 \\
\hline
\end{tabular}




\begin{tabular}{|c|c|c|c|c|}
\hline \multicolumn{5}{|c|}{ Data shown in Fig. 7} \\
\hline \multicolumn{5}{|c|}{ Baseline Blade } \\
\hline \begin{tabular}{|c|} 
Normalized \\
Radial \\
Distance \\
$(\mathrm{r} / \mathrm{R})$ \\
\end{tabular} & \begin{tabular}{|c|} 
Axial Inflow \\
Coefficient \\
Wind Speed \\
$4.5 \mathrm{~m} / \mathrm{s} ; 10 \mathrm{mph}$ \\
\end{tabular} & $\begin{array}{c}\text { Axial Inflow } \\
\text { Coefficient } \\
\text { Wind Speed } \\
6.7 \mathrm{~m} / \mathrm{s} ; 15 \mathrm{mph} \\
\end{array}$ & $\begin{array}{c}\text { Axial Inflow } \\
\text { Coefficient } \\
\text { Wind Speed } \\
8.9 \mathrm{~m} / \mathrm{s} ; 20 \mathrm{mph} \\
\end{array}$ & 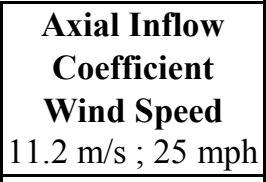 \\
\hline 0.03 and 0.08 & 0.000 & 0.000 & 0.000 & 0.000 \\
\hline 0.13 & 0.086 & 0.172 & 0.196 & 0.175 \\
\hline 0.18 & 0.013 & 0.106 & 0.123 & 0.106 \\
\hline 0.23 & 0.007 & 0.120 & 0.148 & 0.121 \\
\hline 0.28 & 0.054 & 0.165 & 0.173 & 0.133 \\
\hline 0.33 & 0.104 & 0.198 & 0.175 & 0.129 \\
\hline 0.38 & 0.149 & 0.225 & 0.184 & 0.131 \\
\hline 0.43 & 0.181 & 0.243 & 0.192 & 0.135 \\
\hline 0.48 & 0.202 & 0.253 & 0.201 & 0.139 \\
\hline 0.53 & 0.217 & 0.258 & 0.208 & 0.143 \\
\hline 0.58 & 0.230 & 0.261 & 0.216 & 0.147 \\
\hline 0.63 & 0.243 & 0.264 & 0.221 & 0.150 \\
\hline 0.68 & 0.254 & 0.266 & 0.223 & 0.152 \\
\hline 0.73 & 0.265 & 0.268 & 0.227 & 0.154 \\
\hline 0.78 & 0.278 & 0.272 & 0.231 & 0.160 \\
\hline 0.83 & 0.294 & 0.278 & 0.238 & 0.166 \\
\hline 0.88 & 0.310 & 0.288 & 0.251 & 0.177 \\
\hline 0.93 & 0.327 & 0.305 & 0.277 & 0.209 \\
\hline 0.98 & 0.375 & 0.365 & 0.348 & 0.309 \\
\hline \multicolumn{5}{|c|}{ Extended Blade } \\
\hline \begin{tabular}{|c|} 
Normalized \\
Radial \\
Distance \\
$(\mathrm{r} / \mathrm{R})$ \\
\end{tabular} & \begin{tabular}{|c|} 
Axial Inflow \\
Coefficient \\
Wind Speed \\
$4.5 \mathrm{~m} / \mathrm{s} ; 10 \mathrm{mph}$ \\
\end{tabular} & $\begin{array}{c}\text { Axial Inflow } \\
\text { Coefficient } \\
\text { Wind Speed } \\
6.7 \mathrm{~m} / \mathrm{s} ; 15 \mathrm{mph} \\
\end{array}$ & $\begin{array}{c}\text { Axial Inflow } \\
\text { Coefficient } \\
\text { Wind Speed } \\
8.9 \mathrm{~m} / \mathrm{s} ; 20 \mathrm{mph}\end{array}$ & \begin{tabular}{|c|} 
Axial Inflow \\
Coefficient \\
Wind Speed \\
$11.2 \mathrm{~m} / \mathrm{s} ; 25 \mathrm{mph}$ \\
\end{tabular} \\
\hline 0.03 and 0.08 & 0.000 & 0.000 & 0.000 & 0.000 \\
\hline 0.13 & 0.040 & 0.107 & 0.098 & 0.074 \\
\hline 0.18 & 0.001 & 0.087 & 0.093 & 0.079 \\
\hline 0.23 & 0.022 & 0.119 & 0.120 & 0.098 \\
\hline 0.28 & 0.067 & 0.143 & 0.118 & 0.079 \\
\hline 0.33 & 0.109 & 0.164 & 0.121 & 0.075 \\
\hline 0.38 & 0.141 & 0.179 & 0.124 & 0.077 \\
\hline 0.43 & 0.162 & 0.187 & 0.126 & 0.081 \\
\hline 0.48 & 0.176 & 0.192 & 0.130 & 0.092 \\
\hline 0.53 & 0.186 & 0.194 & 0.134 & 0.095 \\
\hline 0.58 & 0.193 & 0.195 & 0.137 & 0.098 \\
\hline 0.63 & 0.198 & 0.194 & 0.141 & 0.102 \\
\hline 0.68 & 0.203 & 0.194 & 0.146 & 0.104 \\
\hline 0.73 & 0.210 & 0.195 & 0.151 & 0.106 \\
\hline 0.78 & 0.220 & 0.199 & 0.156 & 0.110 \\
\hline 0.83 & 0.229 & 0.204 & 0.163 & 0.116 \\
\hline 0.88 & 0.239 & 0.212 & 0.175 & 0.125 \\
\hline 0.93 & 0.255 & 0.230 & 0.199 & 0.145 \\
\hline 0.98 & 0.314 & 0.294 & 0.273 & 0.225 \\
\hline
\end{tabular}




\begin{tabular}{|c|c|c|c|c|c|c|c|c|}
\hline \multicolumn{9}{|c|}{ Data Shown in Fig. 8} \\
\hline \multicolumn{9}{|c|}{ Baseline Blade } \\
\hline $\begin{array}{c}\text { Tip-Speed } \\
\text { Ratio }\end{array}$ & $\begin{array}{c}\text { Cp } \\
0 \text { deg pitch }\end{array}$ & $\begin{array}{c}\text { Cp } \\
1 \text { deg pitch }\end{array}$ & $\begin{array}{c}\text { Cp } \\
2 \text { deg pitch }\end{array}$ & $\begin{array}{c}\text { Cp } \\
3 \text { deg pitch }\end{array}$ & $\begin{array}{c}\text { Cp } \\
4 \text { deg pitch }\end{array}$ & $\begin{array}{c}\text { Cp } \\
5 \text { deg pitch }\end{array}$ & $\begin{array}{c}\text { Cp } \\
6 \text { deg pitch }\end{array}$ & $\begin{array}{c}\text { Cp } \\
7 \text { deg pitch }\end{array}$ \\
\hline 10.58 & 0.084 & 0.134 & 0.168 & 0.187 & 0.182 & 0.132 & 0.026 & - \\
\hline 9.41 & 0.204 & 0.243 & 0.274 & 0.297 & 0.302 & 0.270 & 0.198 & 0.094 \\
\hline 8.47 & 0.282 & 0.314 & 0.341 & 0.362 & 0.369 & 0.347 & 0.295 & 0.219 \\
\hline 7.70 & 0.336 & 0.363 & 0.387 & 0.406 & 0.410 & 0.390 & 0.350 & 0.293 \\
\hline 7.06 & 0.375 & 0.398 & 0.420 & 0.436 & 0.437 & 0.418 & 0.385 & 0.337 \\
\hline 6.51 & 0.405 & 0.426 & 0.444 & 0.457 & 0.454 & 0.436 & 0.407 & 0.367 \\
\hline 6.05 & 0.429 & 0.447 & 0.463 & 0.470 & 0.464 & 0.447 & 0.421 & 0.387 \\
\hline 5.64 & 0.448 & 0.464 & 0.477 & 0.479 & 0.471 & 0.454 & 0.430 & 0.399 \\
\hline 5.29 & 0.460 & 0.475 & 0.483 & 0.483 & 0.474 & 0.458 & 0.436 & 0.408 \\
\hline 4.98 & 0.456 & 0.472 & 0.479 & 0.479 & 0.472 & 0.458 & 0.438 & 0.413 \\
\hline 4.70 & 0.418 & 0.446 & 0.459 & 0.466 & 0.463 & 0.453 & 0.437 & 0.415 \\
\hline 4.46 & 0.381 & 0.404 & 0.425 & 0.439 & 0.443 & 0.441 & 0.430 & 0.413 \\
\hline 4.23 & 0.358 & 0.371 & 0.389 & 0.405 & 0.415 & 0.419 & 0.415 & 0.405 \\
\hline 4.03 & 0.334 & 0.345 & 0.358 & 0.372 & 0.385 & 0.392 & 0.394 & 0.389 \\
\hline 3.85 & 0.301 & 0.321 & 0.331 & 0.343 & 0.356 & 0.366 & 0.370 & 0.369 \\
\hline 3.68 & 0.267 & 0.290 & 0.305 & 0.317 & 0.328 & 0.339 & 0.347 & 0.349 \\
\hline 3.53 & 0.239 & 0.258 & 0.279 & 0.291 & 0.303 & 0.313 & 0.322 & 0.328 \\
\hline 3.39 & 0.212 & 0.233 & 0.250 & 0.268 & 0.278 & 0.290 & 0.299 & 0.307 \\
\hline 3.26 & 0.190 & 0.209 & 0.227 & 0.243 & 0.257 & 0.267 & 0.275 & 0.285 \\
\hline 3.14 & 0.169 & 0.188 & 0.206 & 0.220 & 0.236 & 0.247 & 0.255 & 0.264 \\
\hline 3.02 & 0.151 & 0.168 & 0.185 & 0.201 & 0.214 & 0.228 & 0.237 & 0.245 \\
\hline 2.92 & 0.137 & 0.152 & 0.166 & 0.182 & 0.196 & 0.208 & 0.220 & 0.228 \\
\hline 2.82 & 0.123 & 0.137 & 0.150 & 0.164 & 0.180 & 0.190 & 0.203 & 0.212 \\
\hline 2.73 & 0.111 & 0.124 & 0.136 & 0.149 & 0.163 & 0.176 & 0.185 & 0.197 \\
\hline 2.65 & 0.100 & 0.113 & 0.126 & 0.136 & 0.148 & 0.160 & 0.171 & 0.181 \\
\hline 2.57 & 0.090 & 0.102 & 0.114 & 0.125 & 0.136 & 0.147 & 0.158 & 0.167 \\
\hline 2.49 & 0.082 & 0.094 & 0.104 & 0.114 & 0.125 & 0.135 & 0.145 & 0.154 \\
\hline 2.42 & 0.075 & 0.085 & 0.095 & 0.105 & 0.115 & 0.124 & 0.135 & 0.144 \\
\hline 2.35 & 0.068 & 0.078 & 0.086 & 0.097 & 0.106 & 0.115 & 0.124 & 0.133 \\
\hline 2.29 & 0.062 & 0.072 & 0.080 & 0.089 & 0.098 & 0.106 & 0.114 & 0.123 \\
\hline 2.23 & 0.057 & 0.066 & 0.074 & 0.082 & 0.090 & 0.098 & 0.107 & 0.114 \\
\hline 2.17 & 0.052 & 0.060 & 0.068 & 0.076 & 0.083 & 0.091 & 0.099 & 0.107 \\
\hline 2.12 & 0.048 & 0.055 & 0.063 & 0.070 & 0.077 & 0.085 & 0.092 & 0.099 \\
\hline
\end{tabular}




\begin{tabular}{|c|c|c|c|c|c|c|c|c|}
\hline \multicolumn{9}{|c|}{ Data Shown in Fig. 8 (continued) } \\
\hline \multicolumn{9}{|c|}{ Baseline Blade cut to a $4.5 \mathrm{~m}$ span } \\
\hline $\begin{array}{c}\text { Tip-Speed } \\
\text { Ratio }\end{array}$ & \begin{tabular}{|c|} 
Cp \\
o deg pitch
\end{tabular} & $\begin{array}{c}\text { Cp } \\
1 \text { deg pitch }\end{array}$ & $\begin{array}{c}\text { Cp } \\
2 \text { deg pitch }\end{array}$ & $\begin{array}{c}\text { Cp } \\
\text { 3 deg pitch } \\
\end{array}$ & \begin{tabular}{|c|} 
Cp \\
4 deg pitch
\end{tabular} & \begin{tabular}{|c|} 
Cp \\
5 deg pitch
\end{tabular} & $\begin{array}{c}\text { Cp } \\
6 \text { deg pitch }\end{array}$ & $\begin{array}{c}\text { Cp } \\
7 \text { deg pitch }\end{array}$ \\
\hline 10.82 & - & 0.003 & 0.014 & 0.001 & 0.182 & - & - & - \\
\hline 9.47 & 0.145 & 0.181 & 0.199 & 0.204 & 0.182 & 0.110 & - & - \\
\hline 8.42 & 0.246 & 0.275 & 0.298 & 0.312 & 0.304 & 0.258 & 0.181 & 0.075 \\
\hline 7.58 & 0.311 & 0.336 & 0.357 & 0.372 & 0.368 & 0.338 & 0.284 & 0.209 \\
\hline 6.89 & 0.355 & 0.377 & 0.397 & 0.410 & 0.406 & 0.382 & 0.342 & 0.286 \\
\hline 6.31 & 0.387 & 0.407 & 0.425 & 0.436 & 0.431 & 0.410 & 0.377 & 0.332 \\
\hline 5.83 & 0.412 & 0.430 & 0.445 & 0.453 & 0.446 & 0.428 & 0.399 & 0.362 \\
\hline 5.41 & 0.432 & 0.447 & 0.460 & 0.463 & 0.456 & 0.439 & 0.414 & 0.382 \\
\hline 5.05 & 0.447 & 0.461 & 0.471 & 0.470 & 0.462 & 0.446 & 0.423 & 0.395 \\
\hline 4.74 & 0.457 & 0.469 & 0.475 & 0.473 & 0.464 & 0.449 & 0.429 & 0.403 \\
\hline 4.46 & 0.451 & 0.465 & 0.471 & 0.470 & 0.463 & 0.450 & 0.431 & 0.409 \\
\hline 4.21 & 0.418 & 0.438 & 0.451 & 0.457 & 0.455 & 0.445 & 0.431 & 0.411 \\
\hline 3.99 & 0.386 & 0.402 & 0.418 & 0.429 & 0.435 & 0.433 & 0.424 & 0.409 \\
\hline 3.79 & 0.362 & 0.373 & 0.387 & 0.398 & 0.406 & 0.410 & 0.409 & 0.401 \\
\hline 3.61 & 0.335 & 0.348 & 0.359 & 0.370 & 0.379 & 0.384 & 0.387 & 0.384 \\
\hline 3.44 & 0.301 & 0.320 & 0.332 & 0.343 & 0.352 & 0.360 & 0.363 & 0.364 \\
\hline 3.29 & 0.266 & 0.290 & 0.304 & 0.317 & 0.327 & 0.335 & 0.341 & 0.343 \\
\hline 3.16 & 0.238 & 0.258 & 0.277 & 0.291 & 0.302 & 0.311 & 0.319 & 0.324 \\
\hline 3.03 & 0.213 & 0.230 & 0.249 & 0.266 & 0.276 & 0.289 & 0.296 & 0.304 \\
\hline 2.91 & 0.191 & 0.208 & 0.223 & 0.241 & 0.255 & 0.264 & 0.273 & 0.283 \\
\hline 2.81 & 0.171 & 0.187 & 0.203 & 0.216 & 0.233 & 0.245 & 0.253 & 0.262 \\
\hline 2.71 & 0.152 & 0.168 & 0.184 & 0.197 & 0.209 & 0.225 & 0.235 & 0.243 \\
\hline 2.61 & 0.136 & 0.151 & 0.165 & 0.180 & 0.192 & 0.205 & 0.218 & 0.226 \\
\hline 2.53 & 0.122 & 0.137 & 0.149 & 0.162 & 0.176 & 0.188 & 0.199 & 0.210 \\
\hline 2.44 & 0.111 & 0.123 & 0.136 & 0.148 & 0.161 & 0.173 & 0.183 & 0.194 \\
\hline 2.37 & 0.099 & 0.112 & 0.123 & 0.134 & 0.146 & 0.158 & 0.169 & 0.178 \\
\hline 2.30 & 0.089 & 0.100 & 0.112 & 0.123 & 0.133 & 0.144 & 0.155 & 0.165 \\
\hline 2.23 & 0.081 & 0.091 & 0.102 & 0.113 & 0.124 & 0.132 & 0.141 & 0.152 \\
\hline 2.16 & 0.075 & 0.083 & 0.093 & 0.103 & 0.113 & 0.122 & 0.132 & 0.141 \\
\hline 2.10 & 0.068 & \begin{tabular}{ll|}
0.077 \\
\end{tabular} & 0.085 & 0.094 & 0.103 & 0.112 & 0.121 & 0.130 \\
\hline 2.05 & 0.061 & 0.070 & 0.079 & 0.086 & 0.096 & 0.104 & 0.112 & 0.120 \\
\hline 1.99 & 0.057 & 0.065 & 0.072 & 0.080 & 0.088 & 0.096 & 0.104 & 0.112 \\
\hline 1.94 & 0.052 & \begin{tabular}{|c|}
0.059 \\
\end{tabular} & 0.067 & 0.075 & \begin{tabular}{|c|}
0.081 \\
\end{tabular} & 0.089 & 0.097 & 0.104 \\
\hline 1.89 & 0.048 & 0.054 & 0.062 & 0.069 & 0.076 & 0.082 & 0.090 & 0.097 \\
\hline
\end{tabular}




\begin{tabular}{|c|c|c|c|c|c|c|c|c|}
\hline \multicolumn{9}{|c|}{ Data Shown in Fig. 8 (concluded) } \\
\hline \multicolumn{9}{|c|}{ Baseline Blade cut to a $4.0 \mathrm{~m}$ span } \\
\hline \begin{tabular}{|c|} 
Tip-Speed \\
Ratio \\
\end{tabular} & \begin{tabular}{|c|} 
Cp \\
0 deg pitch
\end{tabular} & \begin{tabular}{|c|} 
Cp \\
1 deg pitch
\end{tabular} & \begin{tabular}{|c|} 
Cp \\
2 deg pitch \\
\end{tabular} & \begin{tabular}{|c|} 
Cp \\
3 deg pitch \\
\end{tabular} & \begin{tabular}{|c|} 
Cp \\
4 deg pitch \\
\end{tabular} & \begin{tabular}{|c|} 
Cp \\
5 deg pitch
\end{tabular} & \begin{tabular}{|c|} 
Cp \\
6 deg pitch
\end{tabular} & $\begin{array}{c}\text { Cp } \\
7 \text { deg pitch }\end{array}$ \\
\hline 9.62 & 0.042 & 0.051 & 0.042 & 0.004 & 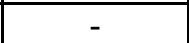 & - & - & - \\
\hline 8.42 & 0.198 & 0.217 & 0.225 & 0.214 & 0.168 & 0.082 & - & - \\
\hline 7.48 & 0.282 & 0.303 & 0.319 & 0.320 & 0.294 & 0.239 & 0.160 & 0.054 \\
\hline 6.73 & 0.336 & 0.355 & 0.370 & 0.375 & 0.360 & 0.324 & 0.268 & 0.194 \\
\hline 6.12 & 0.373 & 0.390 & 0.405 & 0.409 & 0.397 & 0.369 & 0.328 & 0.274 \\
\hline 5.61 & 0.399 & 0.415 & 0.428 & 0.431 & 0.420 & 0.397 & 0.364 & 0.321 \\
\hline 5.18 & 0.418 & 0.433 & 0.444 & 0.445 & 0.435 & 0.415 & 0.388 & 0.352 \\
\hline 4.81 & 0.434 & 0.447 & 0.455 & 0.453 & 0.444 & 0.426 & 0.402 & 0.372 \\
\hline 4.49 & 0.446 & 0.457 & 0.462 & 0.459 & 0.449 & 0.433 & 0.412 & 0.386 \\
\hline 4.21 & 0.453 & 0.462 & 0.464 & 0.461 & 0.451 & 0.437 & 0.418 & 0.394 \\
\hline 3.96 & 0.444 & 0.455 & 0.459 & 0.457 & 0.450 & 0.438 & 0.421 & 0.400 \\
\hline 3.74 & 0.410 & 0.427 & 0.439 & 0.444 & 0.442 & 0.433 & 0.420 & 0.402 \\
\hline 3.54 & 0.383 & 0.395 & 0.406 & 0.416 & 0.423 & 0.422 & 0.414 & 0.400 \\
\hline 3.37 & 0.361 & 0.370 & 0.379 & 0.386 & 0.394 & 0.398 & 0.399 & 0.392 \\
\hline 3.21 & 0.331 & 0.345 & 0.354 & 0.361 & 0.368 & 0.372 & 0.375 & 0.375 \\
\hline 3.06 & 0.298 & 0.316 & 0.328 & 0.338 & 0.344 & 0.349 & 0.352 & 0.354 \\
\hline 2.93 & 0.264 & 0.284 & 0.299 & 0.312 & 0.321 & 0.328 & 0.332 & 0.334 \\
\hline 2.81 & 0.232 & 0.255 & 0.272 & 0.284 & 0.297 & 0.306 & 0.312 & 0.315 \\
\hline 2.69 & 0.210 & 0.225 & 0.245 & 0.261 & 0.271 & 0.284 & 0.291 & 0.297 \\
\hline 2.59 & 0.188 & 0.204 & 0.217 & 0.235 & 0.250 & 0.259 & 0.270 & 0.277 \\
\hline 2.49 & 0.169 & 0.184 & 0.198 & 0.210 & 0.226 & 0.240 & 0.248 & 0.257 \\
\hline 2.41 & 0.151 & 0.166 & 0.179 & 0.192 & 0.204 & 0.218 & 0.229 & 0.238 \\
\hline 2.32 & 0.135 & 0.149 & 0.161 & 0.175 & 0.186 & 0.198 & 0.211 & 0.220 \\
\hline 2.24 & 0.121 & 0.134 & 0.146 & 0.159 & 0.171 & 0.181 & 0.192 & 0.204 \\
\hline 2.17 & 0.108 & 0.121 & 0.132 & 0.144 & 0.156 & 0.168 & 0.176 & 0.189 \\
\hline 2.10 & 0.096 & 0.108 & 0.120 & 0.131 & 0.142 & 0.153 & 0.164 & 0.173 \\
\hline 2.04 & 0.088 & 0.098 & 0.109 & 0.120 & 0.131 & 0.140 & 0.150 & 0.160 \\
\hline 1.98 & 0.080 & 0.089 & 0.099 & 0.110 & 0.119 & 0.129 & 0.137 & 0.147 \\
\hline 1.92 & 0.073 & 0.082 & 0.090 & 0.100 & 0.110 & 0.119 & 0.127 & 0.136 \\
\hline 1.87 & 0.067 & 0.075 & 0.083 & 0.092 & 0.101 & 0.110 & 0.118 & 0.126 \\
\hline 1.82 & 0.061 & 0.069 & 0.077 & 0.084 & 0.092 & 0.101 & 0.109 & 0.118 \\
\hline 1.77 & 0.057 & 0.063 & 0.071 & 0.078 & 0.085 & 0.093 & 0.101 & 0.108 \\
\hline 1.73 & 0.052 & 0.059 & 0.066 & 0.072 & 0.079 & 0.086 & 0.094 & 0.102 \\
\hline 1.68 & 0.049 & 0.054 & 0.061 & 0.068 & 0.074 & 0.080 & 0.087 & 0.094 \\
\hline
\end{tabular}




\section{REPORT DOCUMENTATION PAGE}

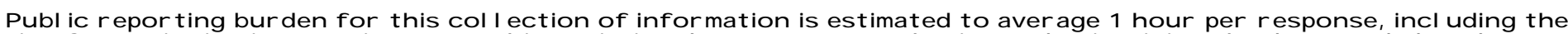
time for reviewing instructions, searching existing dat a sources, gather ing and maint aining the data needed, and

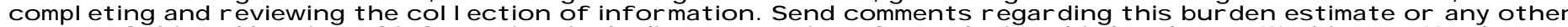

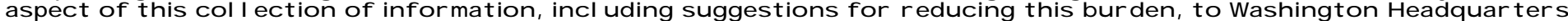

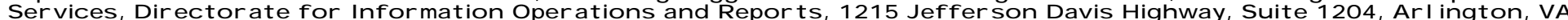

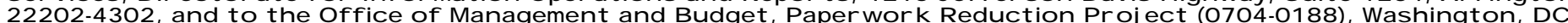
20503

1 .

2.REPORT DATE

April 1999
3. REPORT TYPE AND DATES COVERED Subcontractor Report
4. TITLE AND SUBTITLE

Design of a Tapered and Twisted BI ade for the NREL Combined

Experiment Rotor
5. FUNDING NUMBERS

C: $X A F-4-14076-03$

TA : WE 901110

6. AUTHOR(S)

P. Giguer e, M.D. Selig

7. PERFORMING ORGANIZATION NAME(S) AND ADDRESS(ES)

Department of Aeronautical and Astronautical Engineering

University of III ino is at Urbana-Champaign

8. PERFORMING

ORGANIZATION

REPORT NUMBER

306 Tal bot Labor atory, $104 \mathrm{~S}$. Wright St.

Urbana, III ino is 61801-2935

9. SPONSORING/MONITORING AGENCY NAME(S) AND ADDRESS(ES)

National Renewabl e Energy Laboratory

$1617 \mathrm{Cole} \mathrm{BI}$ d.

Golden, CO 80401-3393

10.SPONSORING/MONITORING AGENCY REPORT NUMBER

SR $-500-26173$

11. SUPPLEMENTARY NOTES

12a. DISTRIBUTION/AVAILABILITY STATEMENT

National Technical Information Service

12b. DISTRIBUTION CODE

U.S. Depart ment of Commerce

5285 Port Royal Road

Springfiel d, VA 22161

13. A B STR A C T (Maximum 200 words)

A tapered/t wisted bl ade was designed to operate on the Combined Experiment Rotor (CER) of the National Renewable Energy Laboratory (NREL), which is a stall-regul ated downwind wind turbine having a rated power of $20 \mathrm{kil}$ owatt. The geometry of the new bl ade set was optimized based on annual energy production subject to the constraints imposed on the design. These constraints wer e mainl y related to scientific needs for fundamental research in $r$ otor aerodynamics. A trade-off study was conducted to determine the effect of the different design constraints. Based on the results of this study, which considered nonl inear twist and taper distributions as well as the NREL S809, S814, S822 and S823 airfoils, a blade having a I inear taper and a nonl inear twist distribution that uses the S809 airfoil from root to tip was sel ected. This blade configuration is the logical continuation of the previous constant-chord twisted and untwisted blade sets and will facil it ate comparison with those earlier blades. Despite the design constraints based on scientific needs, the new blade is more representative of commercial bl ades than the previous bl ade sets.

14. SUBJECT TERMS

15. NUMBER OF PAGES

wind energy, rotor, horizontal -axis wind tur bine, bl ade design

17. SECURITY CLASSIFICATION OF REPORT Uncl assif ied
SECURITY

CLASSIFICATION OF THIS PAGE Uncl assified
19.

\section{SECURITY}

CLASSIFICATION

OF ABSTRACT

Uncl assified
16. PRICE CODE

20. LIMITATION OF

ABSTRACT

$U \mathrm{~L}$ 